\title{
Seismological asperities from the point of view of dynamic rupture modeling: the 2007 Mw6.6 Chuetsu-Oki, Japan, earthquake
}

\author{
Hideo Aochi • Masayuki Yoshimi
}

Received: 30 September 2015 / Accepted: 7 March 2016/Published online: 24 March 2016

(C) The Author(s) 2016. This article is published with open access at Springerlink.com

\begin{abstract}
We study the ground motion simulations based on three finite-source models for the 2007 Mw6.6 Niigata Chuetsu-oki, Japan, earthquake in order to discuss the performance of the input ground motion estimations for the near-field seismic hazard analysis. The three models include a kinematic source inverted from the regional accelerations, a dynamic source on a planar fault with three asperities inferred from the verynear-field ground motion particle motions, and another dynamic source model with conjugate fault segments. The ground motions are calculated for an available 3D geological model using a finite-difference method. For the comparison, we apply a goodness-of-fit score to the ground motion parameters at different stations, including the nearest one that is almost directly above the ruptured fault segments. The dynamic rupture models show good performance. We find that seismologically inferred earthquake asperities on a single fault plane can be expressed with two conjugate segments. The rupture transfer from one segment to another can generate a significant radiation; this could be interpreted as an asperity projected onto a single fault plane. This
\end{abstract}

\footnotetext{
H. Aochi $(\bowtie)$

Bureau de Recherches Géologiques et Minières, DRP/RSV, 3 avenue Claude Guillemin, BP36009 Orléans, Cedex 2, France e-mail: H.Aochi@brgm.fr

M. Yoshimi

Geological Survey of Japan, National Institute of Advanced Industrial Science and Technology, AIST Tsukuba Central 7, 1-1-1 Higashi, Tsukuba, Ibaraki 305-8567, Japan

e-mail: yoshimi.m@aist.go.jp
}

example illustrates the importance of the fault geometry that has to be taken into account when estimating the very-near-field ground motion.

Keywords Fault geometry · Ground motions · Seismic hazard $\cdot$ Niigata Chuetsu-oki earthquake $\cdot$ Dynamic rupture propagation

\section{Introduction}

Predicting the ground motions for any given scenario of an earthquake is an important seismological task for seismic hazard evaluation (Douglas and Aochi 2008). Nowadays, the earthquake model is kinematically constructed based on the statistical analyses of past earthquakes obtained from various inversions or synthetic earthquake scenarios dynamically simulated (e.g., Mai and Beroza 2002; Irikura and Miyake 2011; Song et al. 2013). In some research projects, there have been attempts to carry out the ground motion simulations using the dynamically simulated earthquake models directly (e.g. Olsen et al. 2009). Indeed, for two decades, dynamic rupture models have been more commonly applied to reproduce the ground motions of recent earthquakes, such as the 1992 Landers earthquake (Olsen et al. 1997; Peyrat et al. 2001; Aochi et al. 2003). Furthermore, the characteristics of the ground motion based on the dynamic rupture models are synthetically studied in terms of rupture velocity, fault geometry, heterogeneity, and so on (e.g., Oglesby and Day 2002; Aochi and Olsen 2004; Aochi and Douglas 2006; 
Schmedes and Archuleta 2008; Dunham and Bhat 2008). Regardless of the progress in dynamic rupture modeling, the models are difficult to produce and calibrate. In this paper, we aim to show the applicability and the utility of the dynamic rupture models for the nearfield ground motion simulations applied to the 2007 Mw6.6 Chuetsu-oki, Japan, earthquake.

The 16th July 2007 Chuetsu-oki earthquake (Niigata prefecture, Japan; Fig. 1) led to some damage in Kashiwazaki and the shutdown of the KashiwazakiKariwa Nuclear Power Plant (NPP), located near station KSH. The dense seismological observational networks, the geodetic observations, and the aftershock analyses in this region reveal the complexity of this earthquake in every aspect: source, propagation, and site (e.g., International Atomic Energy Agency 2007). The capability of reproducing the observed records through numerical modeling becomes a key issue for testing our knowledge and understanding of the quantitative seismic hazard assessment at any location, in particular in the very near field of the causal earthquake source area (e.g., Irikura 2010). This paper focuses on the input ground motion at the nearest seismological observations - the borehole data within the site of Kashiwazaki-Kariwa NPP (KSH-SG4). Utilizing the best available 3D geological model, we carry out the ground motion simulations based on different earthquake source models including both kinematic and dynamic descriptions. The purpose was to emphasize how kinematically inferred earthquake asperities look from the dynamic rupture models and to discuss the applicability of the dynamically simulated source models for estimating input ground motion.
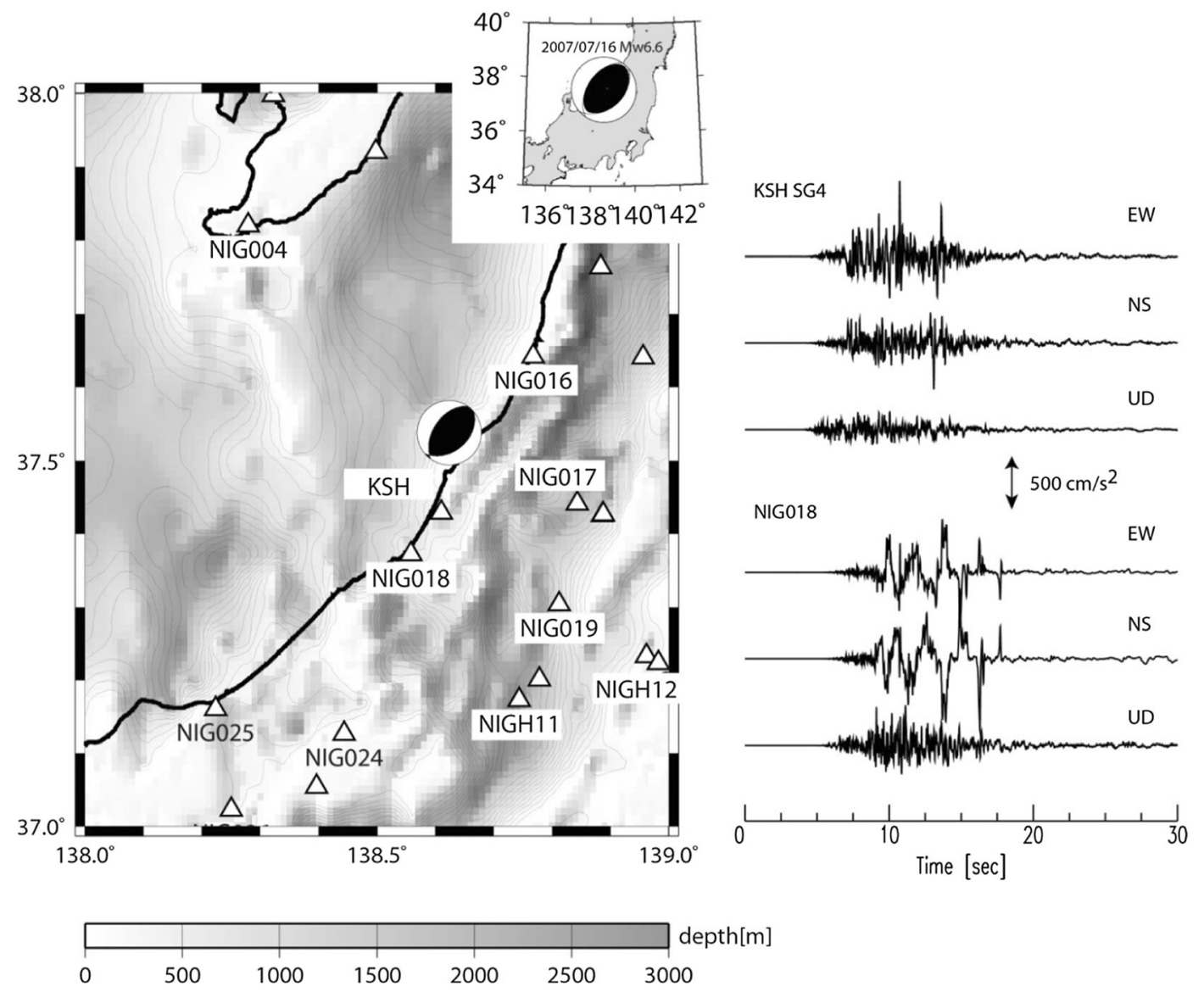

Fig. 1 Map of the studied earthquake and area showing depth contours to the top of the Teradomari formation (Middle to Upper Miocene Mudstones), approximately corresponding to $V_{\mathrm{s}}=1,000 \mathrm{~m} / \mathrm{s}$, from the $3 \mathrm{D}$ geological model (contours every $200 \mathrm{~m}$ ) proposed by Sekiguchi et al. (2009). Triangles represent

the permanent seismological observation networks, and the names are given for those which are going to be used in this study. The acceleration records are at the two nearest stations, KSH (SG4 at depth of $250 \mathrm{~m}$ ) and NIG018. No frequency filter is applied 


\section{Source models of the 2007 Chuetsu-Oki earthquake}

Figure 2 summarizes three source models for the 2007 Chuetsu-oki earthquake used in this study. Various researchers used inversion to obtain kinematic descriptions of the source process. The fault orientation (SEor NW-dipping thrust faulting) was not evident just after the earthquake mainly because the estimated rupture zone is off the coast and the routinely determined location of the aftershocks were inaccurate (Aoi et al. 2008). The observed strong ground motion along the coastline suggested a NW-dipping fault such that the ground motion could be influenced by rupture directivity. However, the interpretation for faulting based on a SEdipping faulting became widely accepted (e.g., Miyake et al. 2010) according to the relocation of the aftershocks from temporary observation networks (e.g., Shinohara et al. 2008; Kato et al. 2008). For this study, we adopt one of the SE-dipping fault models, model B of Aoi et al. (2008), as a reference, though we refer to it as model K (Fig. 2). This model was also used in previous ground motion simulations (Aochi et al. 2013a).

The strong ground motion observed in the near field (a distance from the ruptured fault plane closer than $10 \mathrm{~km}$ ) was the subject of a major debate about the

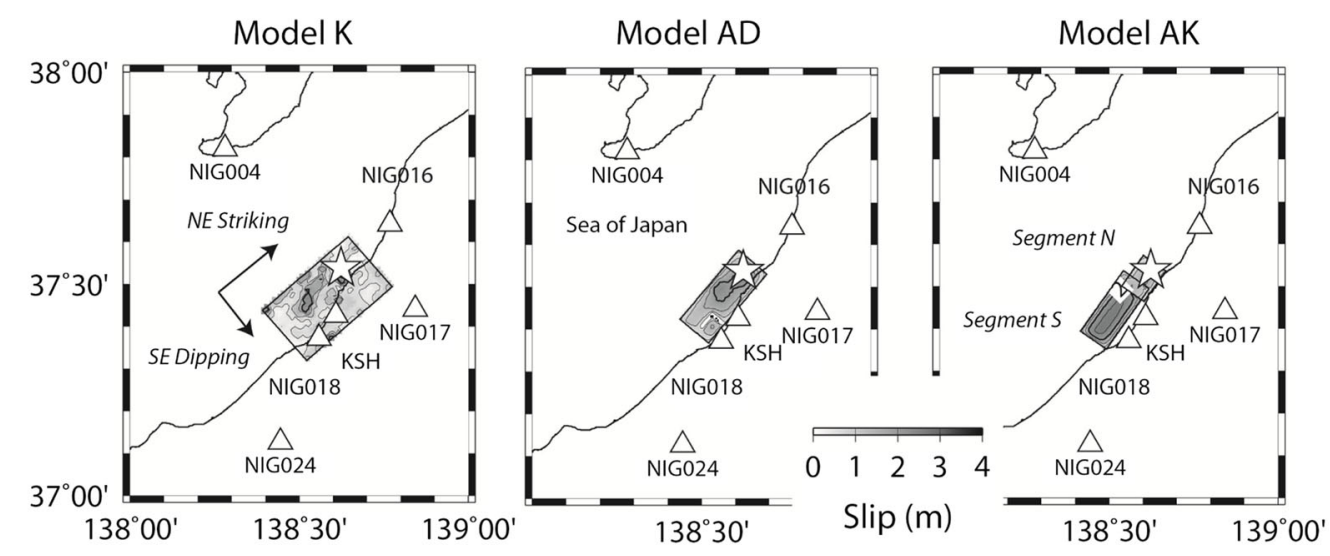

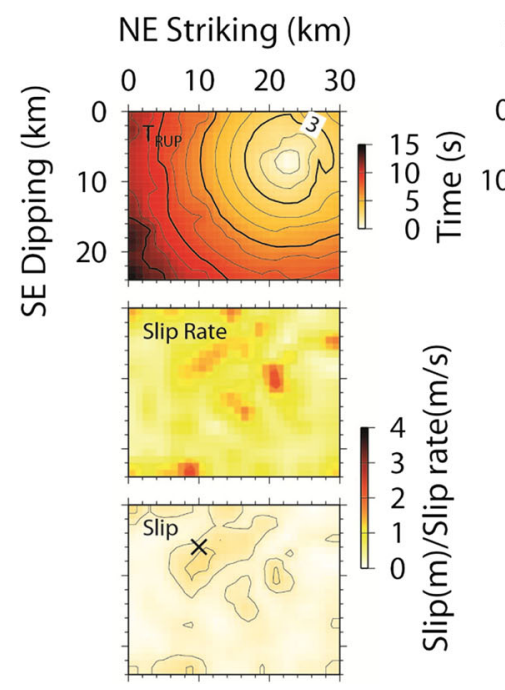

Fig. 2 Map view showing the geometry of the three source models and the locations of stations. Model K: a kinematic source model derived from model B of Aoi et al. (2008). Model AD: a dynamic source model with three strong motion generation areas simulated in Aochi and Dupros (2011). Model AK: a dynamic source model with rupture on two cross-cutting faults (NW- and SE-dipping segments in the north and south, respectively)
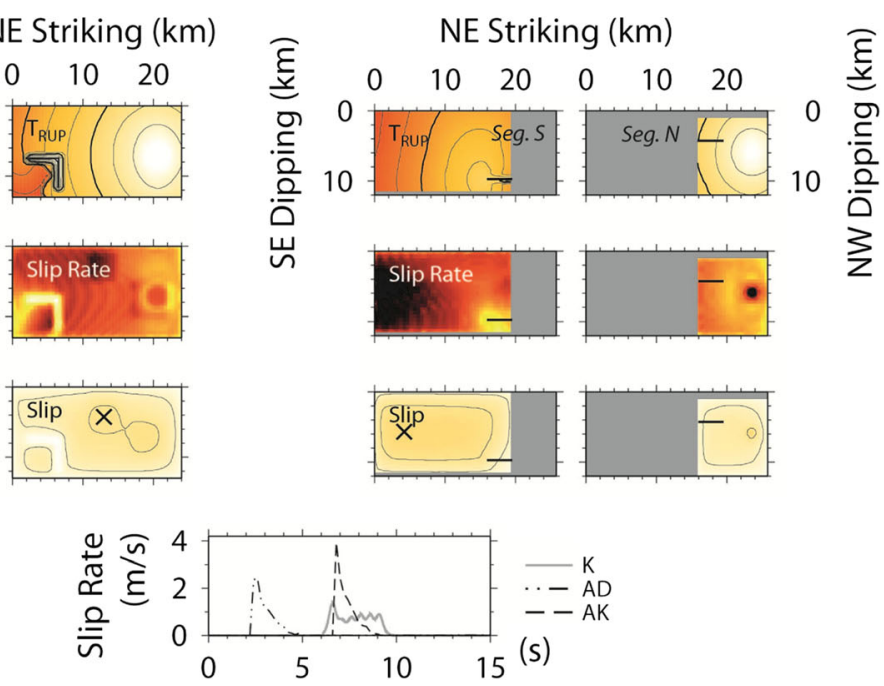

simulated in Aochi and Kato (2010). Stars represent the epicenter locations in the map. In the bottom, the rupture time $\left(T_{\mathrm{RUP}}\right)$, maximum slip rate, and final slip distribution are shown, respectively, with the same scale. For the points of the maximum slip in the three models (denoted by a cross), slip rate evolutions are illustrated at the bottom 
reliability of seismic hazard estimation (Strasser and Bommer 2009; Baumann and Dalguer 2014). The nearest seismic stations (KSH and NIG018; Figs. 1 and 2) are located above the inferred ruptured area along the fault strike. The ground motion at these stations is significantly affected by near-field effects of the earthquake source, such as asperity locations. They were not used in the inversion of Aoi et al. (2008). Irikura (2008) proposed a characteristic model consisting of three asperities, identified as strong motion generation areas (SMGAs). These localized asperities should produce recognizable phases in the seismograms. This characteristic earthquake model was further studied by dynamic modeling assuming a slip-weakening friction law (Aochi and Dupros 2011) and re-illustrated in Fig. 3. From the dynamic point of view, these SMGAs correspond to areas that have stress drops two times larger than the rest of the fault area. This is consistent with the generalized strong motion recipe of Irikura and Miyake (2011). Irikura (2008) proposed that the rupture of the third asperity located in the southernmost end was in the opposite direction of the general southward rupture propagation of this earthquake (multi-hypocenter model). In order to reproduce this effect dynamically, the third asperity needs to be partially surrounded by barriers so that the rupture first moves to the southern edge of the asperity and then ruptures to the northern edge (see the snapshot at $8.3 \mathrm{~s}$ in Fig. 3). This dynamic model is presented as model AD.

Most geodetic studies, on the other hand, propose two segmented, conjugate fault planes (Aoki et al. 2008; Nishimura et al. 2008), which were also inferred from the most accurate aftershock distributions (Shinohara et al. 2008; Kato et al. 2008). Aochi and Kato (2010) previously carried out dynamic rupture simulations for the conjugate fault geometry consisting of a northern NW-dipping segment (segment N) and a southern SEdipping one (segment $\mathrm{S}$ ). They varied the intersection angle and the overlapping distance, as illustrated in Fig. 4. Among their 45 simulations, only 14 show a sequential rupture transfer from one to another segment. We adopt one scenario in which the model parameters are moderate: a frictional coefficient of 0.3 , an overlapping distance of two segments of $4 \mathrm{~km}$, and a dipping angle of SE-dipping fault of $45^{\circ}$. This is designated as model AK.

\section{Numerical simulations of ground motion}

\subsection{Simulation methods}

The complexity of the 3D geological structure is well known in this region due to its complex tectonics. Aochi et al. (2013a) used the three available structure models of this region (Kato et al. 2008; Fujiwara et al. 2009; Sekiguchi et al. 2009) for ground motion simulations and discussed the validity of each model. Ground motion using the 3D structure obtained by tomography (Kato et al. 2008) shows a good coherence on rock sites that are situated close to each other. On the other hand, the models calibrated based on the geological map and the geophysical cross-sections (Fujiwara et al. 2009; Sekiguchi et al. 2009) are generally suitable for the soft sites. However, even when the models are good enough for the direct waves at certain stations, it is still difficult
Fig. 3 Dynamic model parameters (initial shear stress, $\tau_{0}$; peak strength, $\tau_{\mathrm{p}}$; dynamic stress, $\tau_{\mathrm{r}}$; and critical slip displacement, $D_{\text {c }}$ ) and snapshots of slip velocity and shear stress for source model AD - dynamically simulated as rupture on a single fault plane with three asperities (modified after Aochi and Dupros 2011). Note that the slip-weakening rate, $\left(\tau_{\mathrm{p}}-\tau_{\mathrm{r}}\right) / D_{\mathrm{c}}$, is the same everywhere

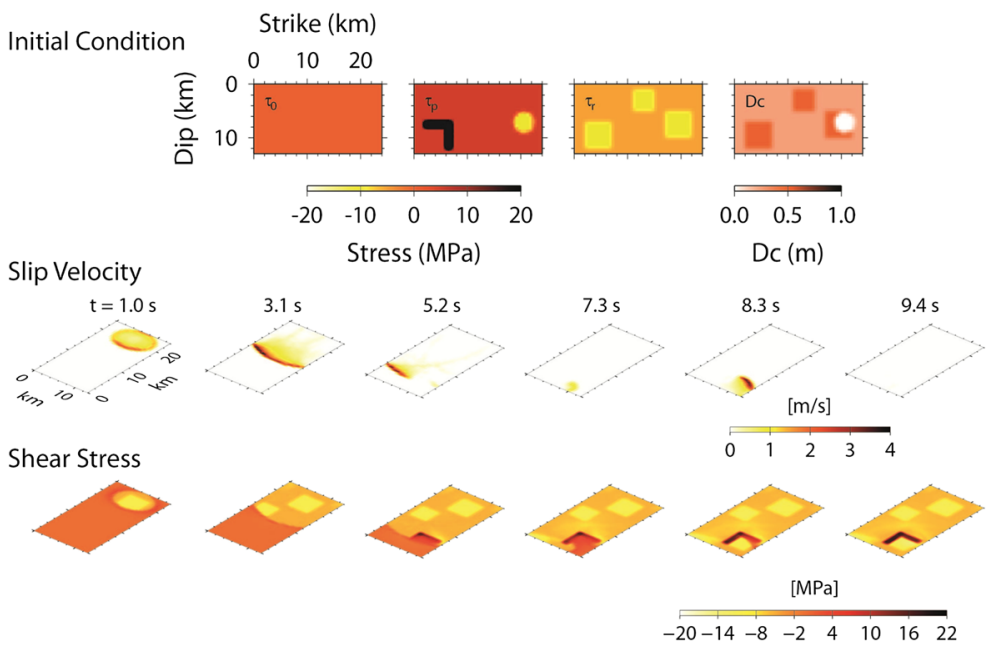




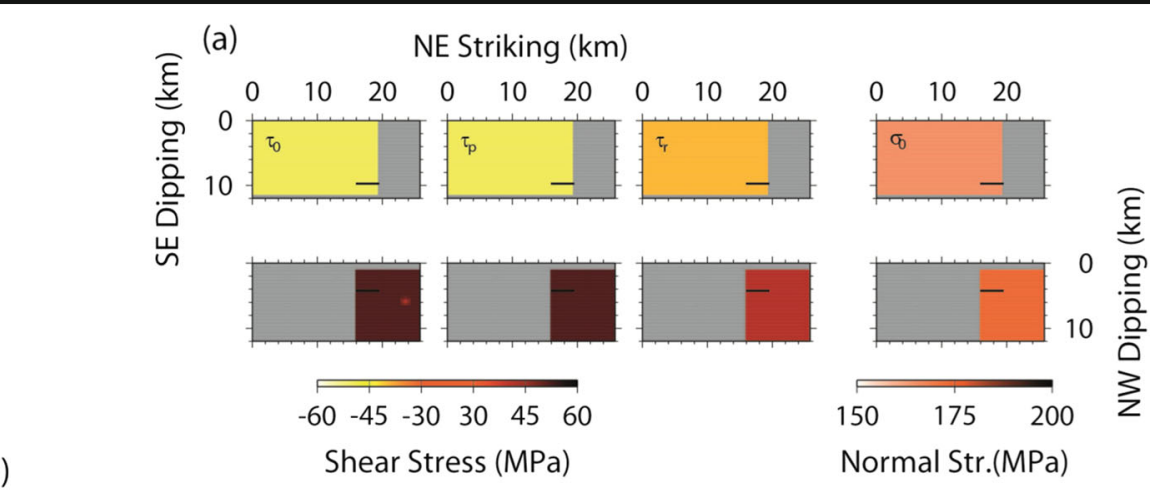

(b)

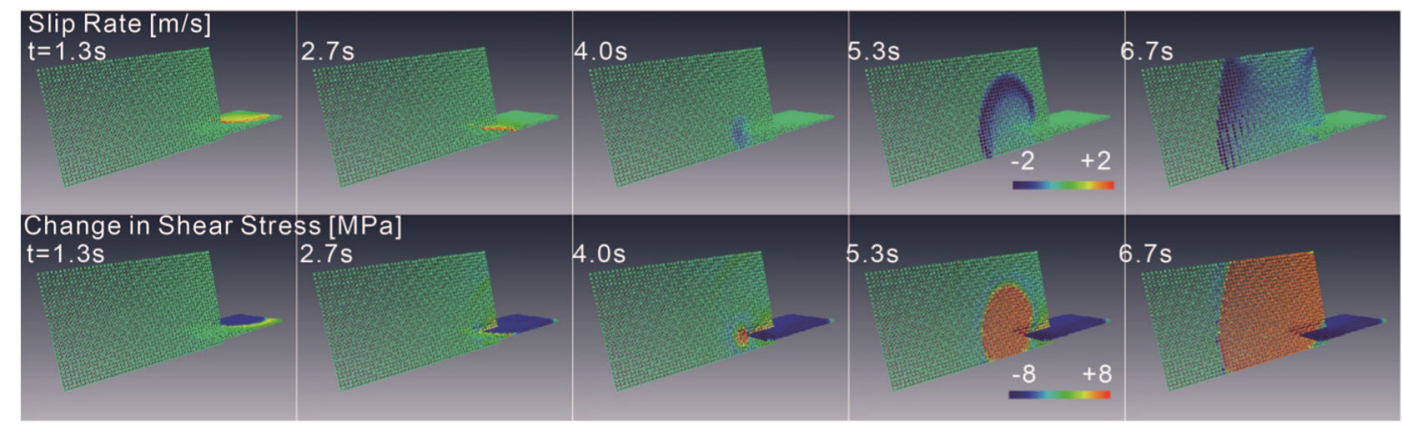

Fig. 4 Dynamic model parameters (initial shear stress, $\tau_{0}$; peak strength, $\tau_{\mathrm{p}}$; dynamic stress, $\tau_{\mathrm{r}}$; and initial normal stress, $\sigma_{0}$. Note that the slip-weakening rate is $30 \mathrm{MPa} / \mathrm{m}$ and is given everywhere) and snapshots of the slip rate and shear stress for the dynamic rupture process (model AK) on two conjugate fault segments (modified after Aochi and Kato 2010)

models $\mathrm{AD}$ and $\mathrm{AK}$ have shorter rupture dimensions. The slip velocity function is also smooth (lower peak and longer duration) in model $\mathrm{K}$ and is shaper in $\mathrm{AD}$ and AK.

\subsection{Simulation results}

Figures 5, 6, and 7 show the simulated ground motions for the nearby stations. For model K, the synthetic ground motions have been presented by Aochi et al. (2013a). The dynamic rupture models (models AD and AK) were computed using the 3D geological model. The ground motions are aligned at the origin time of each simulation which coincides with the origin time of the hypocenter (10:13:22.16 local time). All ground motions are bandpass-filtered between 0.1 and $1.0 \mathrm{~Hz}$. The kinematic model $\mathrm{K}$ uses a simpler 1D structure. Using only a portion (14 s around the direct S wave's arrival) of the seismograms, the reconstruction of the full waves in a 3D structure does not always ensure the coherent fitting of the waveforms even within this frequency range. At the nearest station, NIG018, it is known that the soft soil had been subjected to has a large rupture area, while the dynamic rupture 


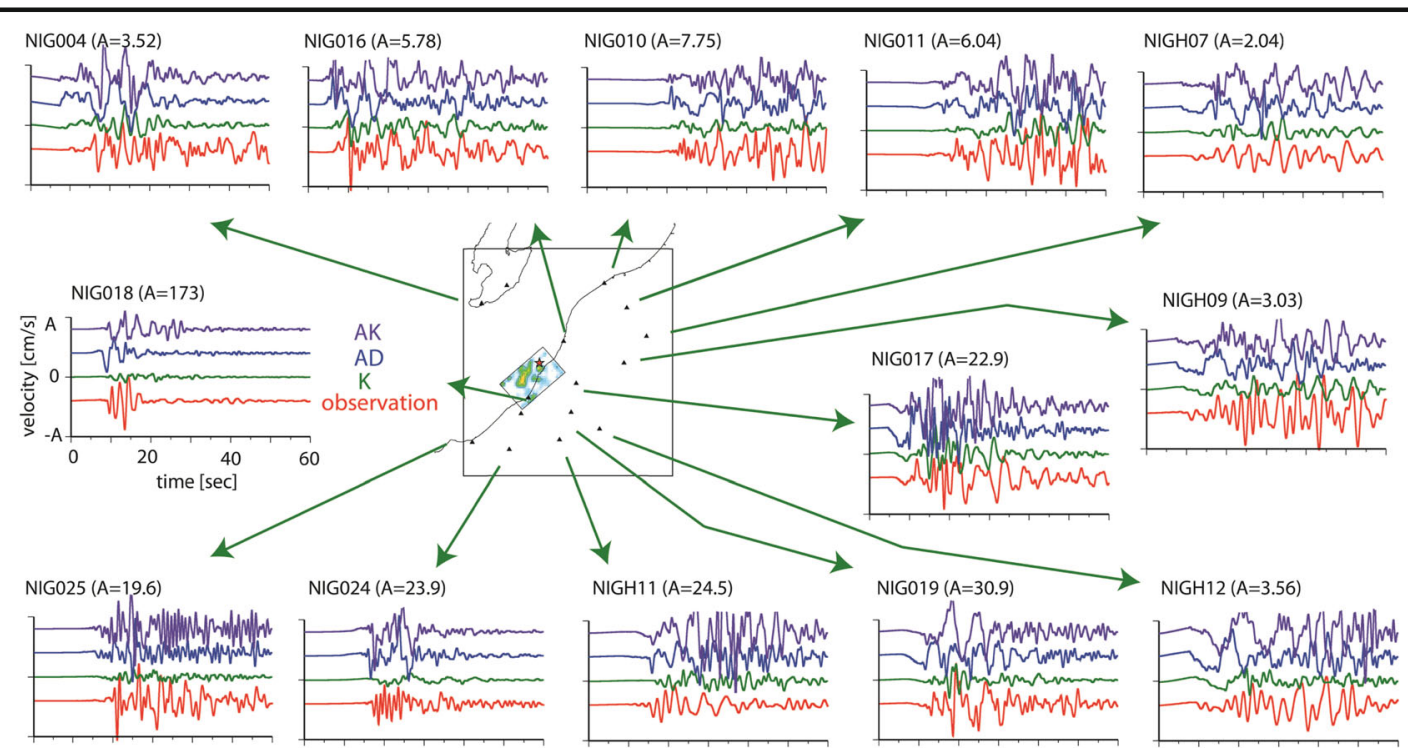

Fig. 5 Comparison of the synthetic EW ground motion from the three source models (K, AD, and AK) with the recorded EW velocity. The ground motions were filtered between 0.1 and $1.0 \mathrm{~Hz}$. For reference, the source model $\mathrm{K}$ is illustrated on the map

liquefaction (Fig. 1) so that the synthetic ground motions cannot be compared directly to the observations.

It is difficult to capture the waveform characteristics precisely in the backward direction of the rupture propagation, namely, in the northeast area (NIG10 and NIG11). However, in the forward direction in the southwest area (NIG024 and NIG025), we find that the characteristic waveforms are better simulated by the dynamic model (AK) than by the kinematic model (K). This is an important feature. The kinematic model is based on an inversion that might have missed or underestimated significant behavior of the rupture process due to a priori constraints or smoothing of the inversion. Therefore, the source model might underestimate the strong ground motions that are closely related to the source process. The dynamic models AD and AK produce similar waveforms, in particular at NIG024, NIG025, NIG004, and NIG019, and seem to be closer to the observations than model K. The similarity of the resultant ground motions for the two models, $\mathrm{AD}$ and $\mathrm{AK}$, indicates that the

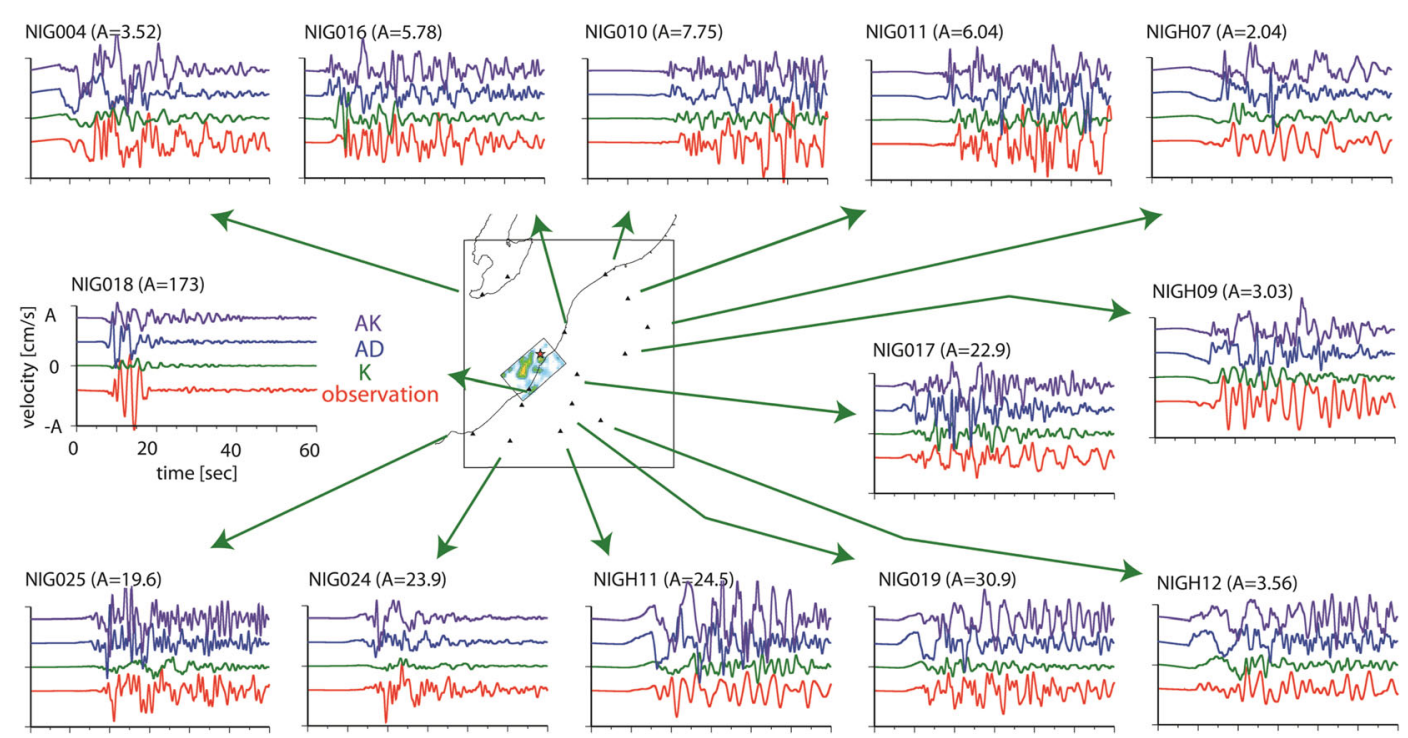

Fig. 6 Comparison of the synthetic NS ground motion from the three source models (K, AD, and AK) with the recorded NS velocity. The ground motions were filtered between 0.1 and $1.0 \mathrm{~Hz}$. For reference, the source model $\mathrm{K}$ is illustrated on the map 


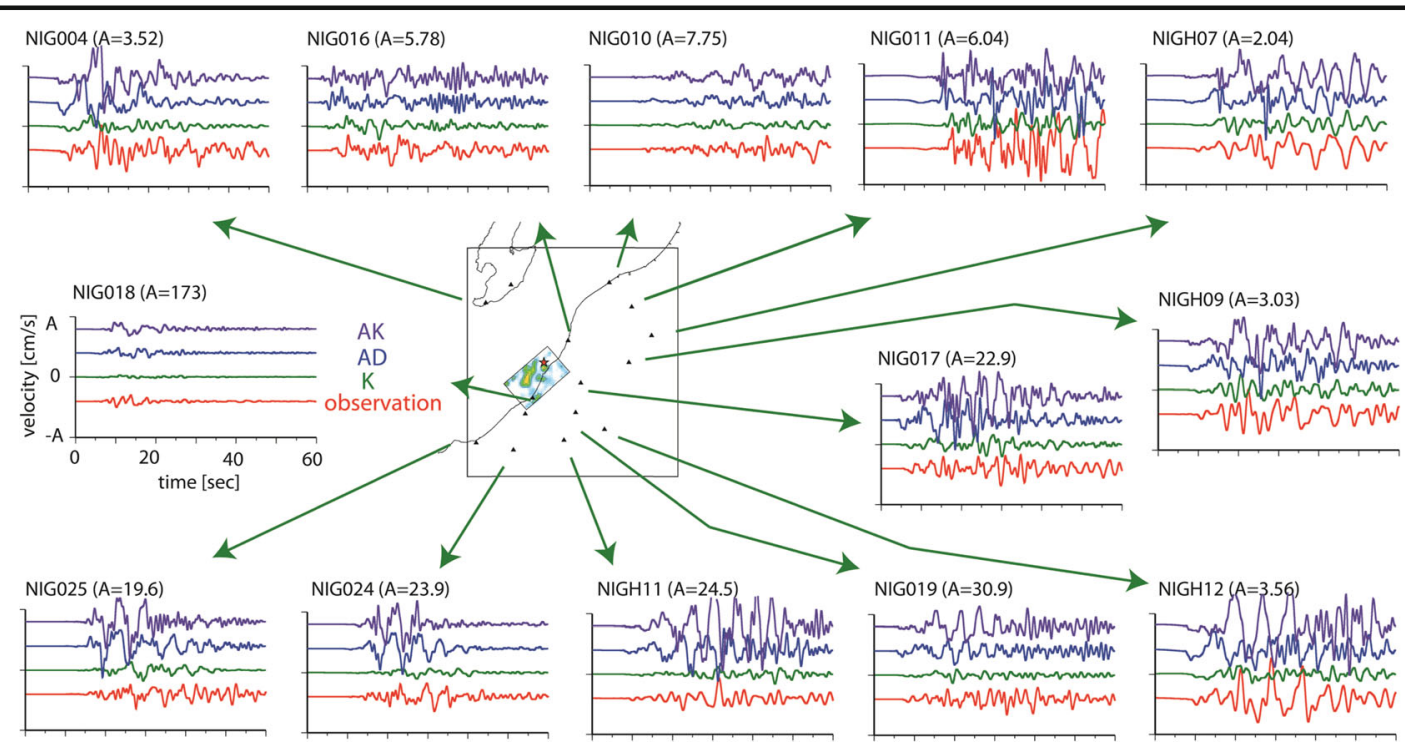

Fig. 7 Comparison of the synthetic UD ground motion from the three source models (K, AD, and AK) with the recorded UD velocity. The ground motions were filtered between 0.1 and $1.0 \mathrm{~Hz}$. For reference, the source model $\mathrm{K}$ is illustrated on the map

asperities inferred on a single fault plane can be represented by the geometrical irregularities of the fault system.

In Fig. 8, we compare two additional simulations in which we use either segment ( $\mathrm{N}$ only or $\mathrm{S}$ only) of model AK to clarify the contribution of the non-planar fault structure. At the closest KSH station, the contribution is clear. The main features of the waveforms are reproduced by segment $\mathrm{S}$, which is closer to $\mathrm{KSH}$ and releases $71 \%$ of the total seismic energy. On the other
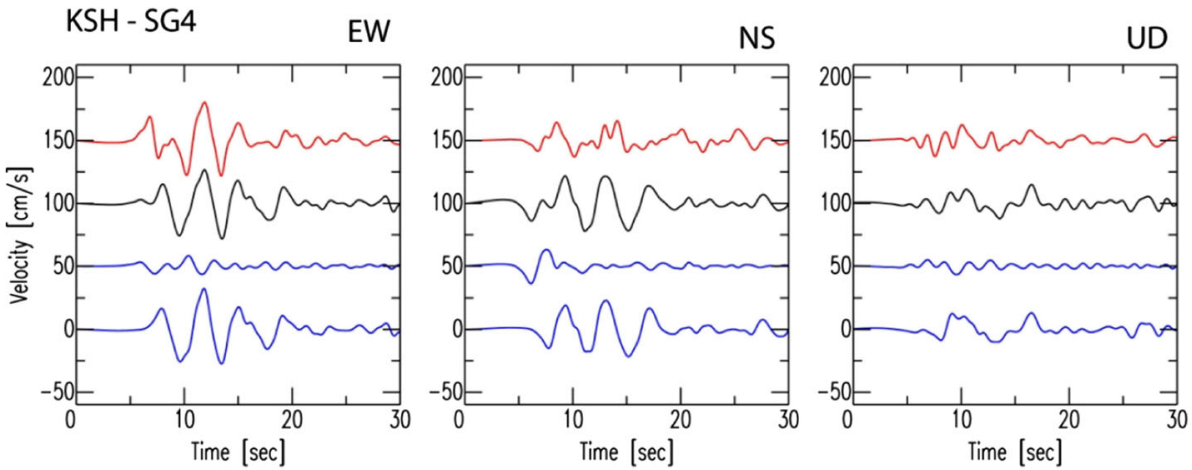

Observation

Model AK (=S+N)

Segment $\mathrm{N}$

Segment S
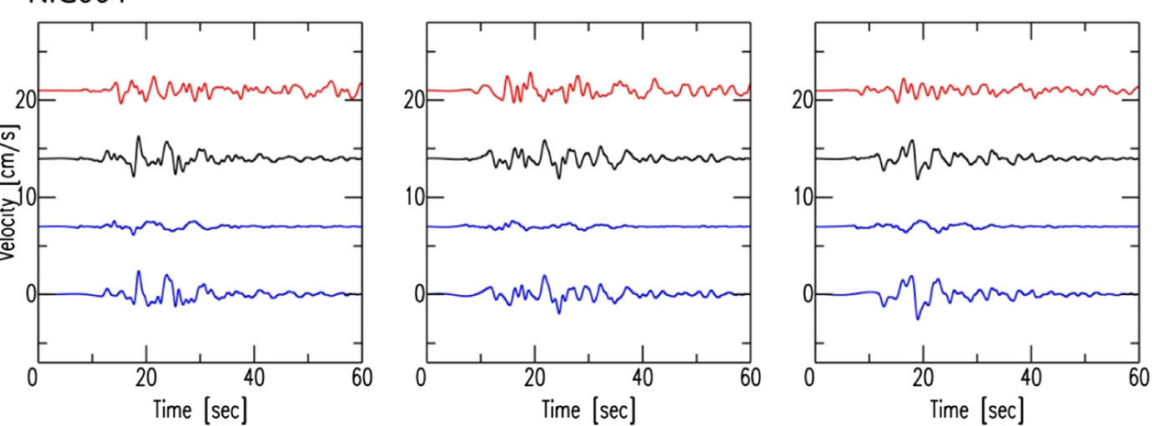

Observation

Model AK $(=\mathrm{S}+\mathrm{N})$

Segment N

Segment S

Fig. 8 Comparison of the synthetic ground motions from either segment (segment $\mathrm{N}$ or S only) of model AK with the recorded velocity. The ground motions were filtered between 0.1 and $1.0 \mathrm{~Hz}$. For reference, model AK (namely, the summation of segments $\mathrm{N}$ and $\mathrm{S}$ ) is also shown 
hand, it is observed that the first pulse is represented by segment N. Such identification becomes difficult at NIG004 as the wave propagation is perturbed during a longer propagation distance. We also compare the final displacement field on the ground surface among models $\mathrm{K}, \mathrm{AD}$, and $\mathrm{AK}$ in Fig. 9 since two fault segments are proposed by geodetic observation (Aoki et al. 2008; Nishimura et al. 2008). A difference is hardly found in the vertical component (UD). In the horizontal components, model AK generates a clearer change in trend, although, again, the field is governed principally by segment $\mathrm{S}$. The comparison between the planar models (K and $\mathrm{AD}$ ) and the non-planar one (AK) has important implications for seismic hazard. Given that it is difficult to identify a priori any asperities on a fault plane before an earthquake, it may be more important to determine the fault structure first.

\section{Criteria for ground motion estimation}

This paper does not aim to improve the model parameters, but tries to show the performance of different earthquake models in generating the ground motion, in particular the performance of the two dynamic rupture models. Although inversion of dynamic rupture parameters has been done for a decade (Peyrat et al. 2004; Ruiz and Madariaga 2011; Douilly et al. 2015), the number of inverted model parameters is usually limited to about 10 due to the high nonlinearity of the system and computational costs. This means that one cannot expect the same degree of spatial or temporal resolution as found in kinematic inversions unless the model parameters of dynamic rupture are constrained by kinematic inversion results (e.g., Peyrat et al. 2004). For the purpose of the ground motion prediction for seismic hazard, the engineers are more interested in the ground motion parameters than in coherent waveforms. Aochi and Douglas (2006) proposed to compare statistically the ground motion parameters at numerous points from the simulations with the ground motion prediction equations in terms of peak ground acceleration (PGA), peak ground velocity (PGV), response spectral acceleration, Arias intensity, and relative significant duration.

Olsen and Mayhew (2010) propose a goodness-of-fit (GOF) criterion for the validation of the broadband synthetics, which consists of different tests on ground motion metrics. The GOF score (normalized to 100) is defined as the complementary error function (erfc) of a normalized residual, NR (Olsen and Mayhew 2010)

$$
\mathrm{GOF}=100 \times \operatorname{erfc}(\mathrm{NR}), \text { where } \mathrm{NR}=\frac{2|x-y|}{x+y}
$$
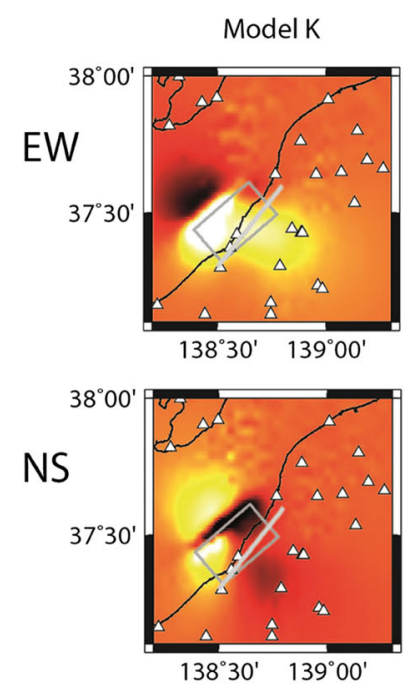

Model AD
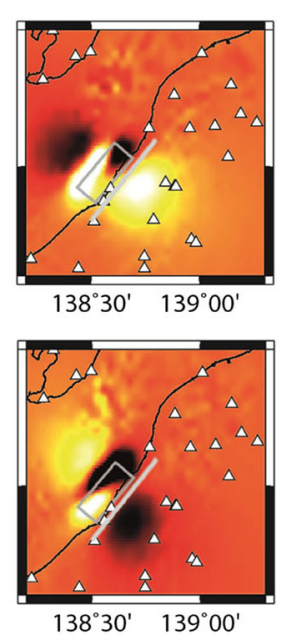

Model AK
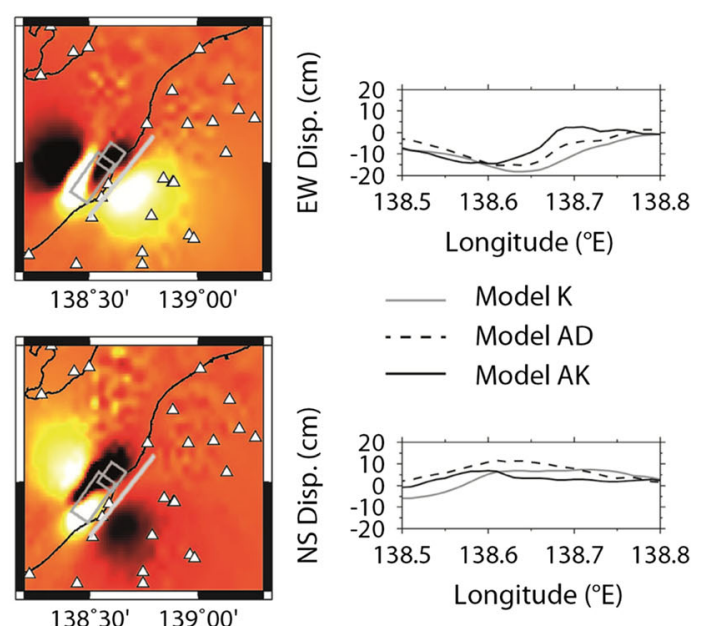

... Model AD

Model AK

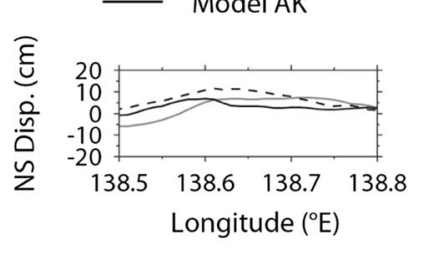

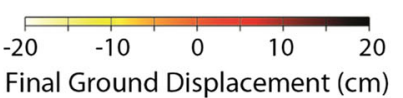

Fig. 9 Comparison of the synthetic final ground displacement in the EW and NS components from the three source models (K, AD, and $\mathrm{AK})$. The causal fault planes are projected on the map. The profiles are shown along a white line on the map, along the coastline 
where $x$ and $y$ are two sets of positive scalar metrics. By associating a weight on the GOF score calculated for each of the metrics, the average GOF score is obtained. Olsen and Mayhew (2010) used the metrics consisting of PGA, PGV, peak ground displacement (PGD), averaged response spectral acceleration (RS), Fourier spectrum (FS), energy duration (DUR), and cumulative energy (ENER) for broadband synthetics between 0.1 and $10 \mathrm{~Hz}$ for the $2008 \mathrm{Mw} 5.4$ Chino Hills earthquake.

In this paper, our simulations are limited to low frequencies. We define the GOF score here as simply an equally weighted average of PGV, PGD, RS (1-10, 4-10, 2-4, and 1-2 s), FS (0.1-1, 0.1-0.25, 0.25-0.5, and $0.5-1.0 \mathrm{~Hz}$ ), DUR, and ENER for the synthetics with respect to the observed seismograms filtered between 0.1 and $1.0 \mathrm{~Hz}$, as already shown in Figs. 5, 6, and 7. Figure 10 shows the GOF scores calculated for the waveforms based on models $\mathrm{K}, \mathrm{AD}$, and $\mathrm{AK}$ at surrounding stations; the detailed scores are shown in Tables 1, 2, and 3 of the Appendix for each ground motion parameter to figure out the impacts in the synthetic seismograms. It is generally considered that the score is "excellent" for more than $80 \%$, "good" for more than $60 \%$, "fair" for more than $40 \%$, and "poor" for the rest. As observed in the waveform comparison in the previous section, the GOF scores for both $\mathrm{AD}$ and
AK models are generally better than those from the kinematic model $(\mathrm{K})$. One of the reasons is that the simulations using model $\mathrm{K}$ were not computed using the 3D geological model. However, we think the principal reason is that the kinematic model may have smoothed the rupture process itself because of the way in which it was originally determined by inversion, e.g., constraints on the source time function and sub-fault size. The dynamic rupture model, on the other hand, can naturally describe any drastic change in the rupture process. We also note that at particular stations, the GOF scores are not good for any source model. For example, stations NIG010 and NIG011 are located relatively far from the source in the Niigata basin, where the surface waves become dominant and continue shaking until the end of the calculation ( $60 \mathrm{~s}$ ). This is one reason why the score is not good. On the other hand, we know that the nearest station, NIG018 (in Kashiwazaki basin), is at a site that liquefied; it is not possible to compare the scores when the ground motion simulation is based on a linear-elastic calculation. However, these stations are also included in the averaged GOF scores, which are still in the "fair" range for the dynamic source models $\mathrm{AD}$ and $\mathrm{AK}$. Although the statistical analysis on the synthetics provides a means to quantify how good the results are among the different models, one should still try to understand the basic features of each seismogram.

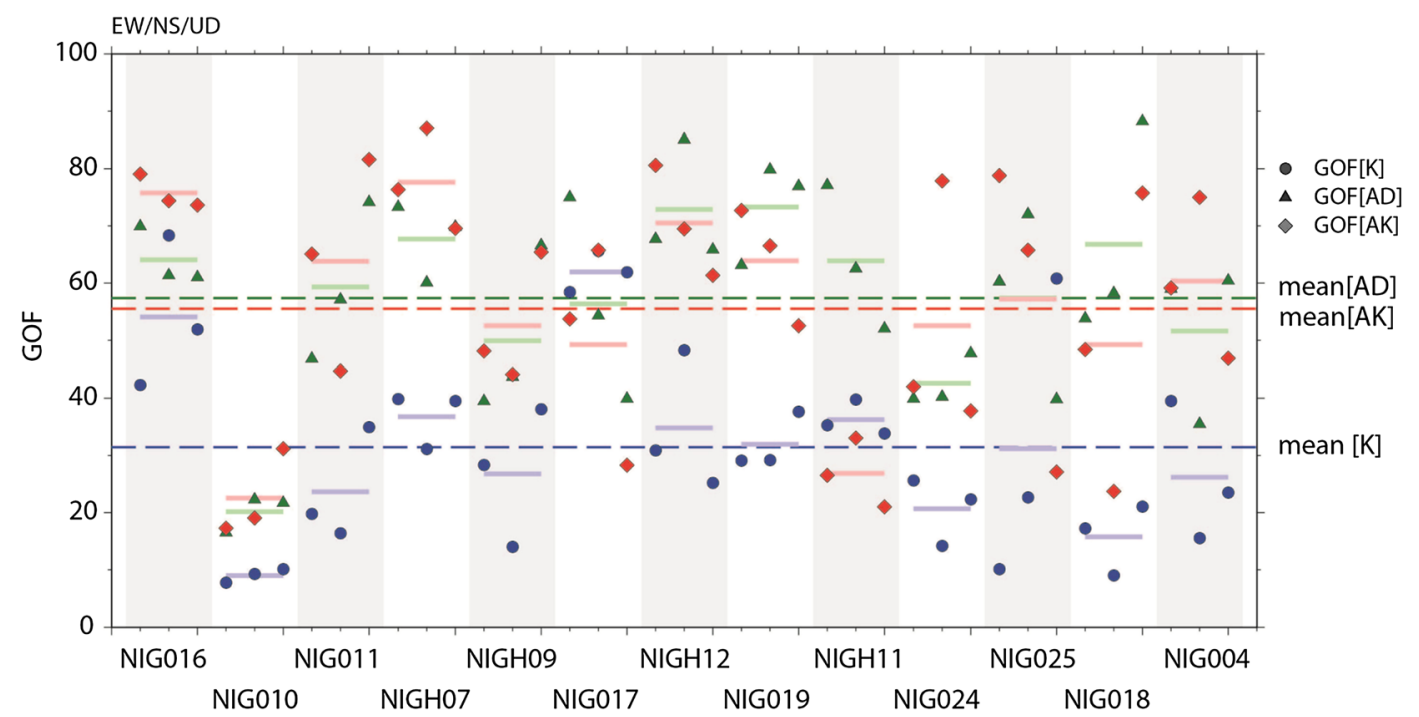

Fig. 10 Comparison of the GOF scores for the synthetics from the three source models $(\mathrm{K}, \mathrm{AD}$, and $\mathrm{AK})$ with respect to the observed seismograms. The GOF score is an average of the six metrics (PGV, PGD, DUR, RS, FS, and ENER) calculated from the waveforms filtered between 0.1 and $1.0 \mathrm{~Hz}$. Broken line shows the average GOF score of each source model over all the stations. Thick short line is the GOF score averaged for each station. GOF scales are from 0 (poor) to 100 (excellent). The detailed scores by each ground motion parameter are shown in Tables A1, A2 and A3 of the Appendix 
Kristekova et al. (2009) proposed a method to evaluate a GOF score in the time-frequency space in order to judge the local variation of the fit between the data and synthetic waveforms. Figure 11 shows the GOF score (normalized to 10 ) on the time-frequency envelope between the observed and synthetic ground velocities at station $\mathrm{KSH}-\mathrm{SG} 4$ for all three components. Compared to the kinematic model $\mathrm{K}$, the dynamic model $\mathrm{AD}$ for this station is slightly different for the EW component, but quite different for the NS component. This figure confirms that the dynamic model AK shows similar scores over the time-frequency range. The colored (yellow + orange) area of model AK is slightly smaller than in model K (by $23 \%$ for the EW component). This comparison of models shows that the dynamic model can generate input ground motion equally well as the kinematic model. This suggests that a hybrid approach, i.e., combining a low-frequency dynamic rupture with any stochastic approach, could be used for generating the broadband ground motion in future applications, as suggested with various finite-source models (e.g., Graves and Pitarka 2015; Crempien and Archuleta 2015; Olsen and Takedatsu 2015).

\section{Discussion and summary}

The aim of this paper was to examine the performance of the dynamically simulated earthquake ruptures in computing ground motion for the purpose of quantitative seismic hazard analysis. For the 2007 Mw6.6 Chuetsu-oki, Japan, earthquake, we compute ground motion in a $3 \mathrm{D}$ geological model using a kinematic source model and two dynamic source models. To quantify the performance of the models, we apply a GOF criterion to the simulated ground motions. From the comparisons, we find that the kinematic model does not always have the best performance in reproducing the characteristics of the strong ground motion. In particular, it does not work well in the very near field and in the forward direction of the rupture propagation. This is probably because an abrupt change in the rupture
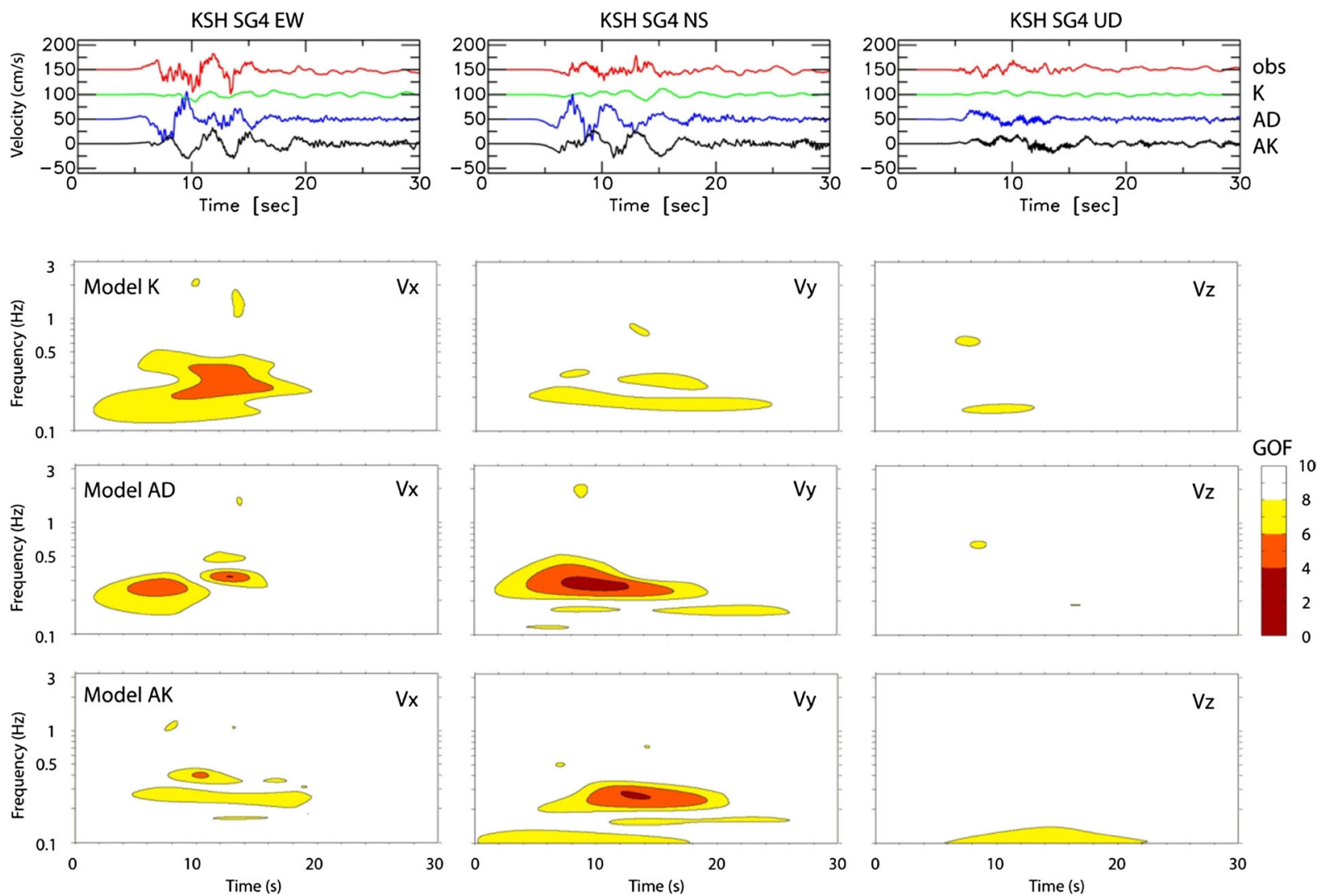

Fig. 11 Time-frequency envelope GOF for the synthetics at SKH-SG4. The three source models are compared for three components ( $x$ : EW, $y$ : NS, and $z$ : UD) of the velocity seismograms. GOF scales are from 0 (poor) to 10 (excellent) 
process (rupture onset and changes in rupture velocity) may not be well simulated by the kinematic description. Two dynamic rupture models produce a similar ground motion radiation. However, the model with the asperities distributed on a single fault plane might be a projection of the rupture process on conjugate fault segments. The rupture process changes the wave radiation naturally due to the geometrical irregularities. From this perspective, the dynamic rupture model on a complex fault geometry produces a reasonable rupture scenario and wave radiation for practical applications.

For the 2007 Chuetsu-oki earthquake, the conjugate segments might be a reasonable causal source model, as inferred from the geodetic analyses (Nishimura et al. 2008; Aoki et al. 2008). Although the model parameters could be calibrated better, the rupture process on each segment could be very simple, represented by three phases: first, rupture on the NW-dipping segment; second, a dynamic rupture transfer between conjugate segments (which changes the wave radiation); and third, rupture on the SE-dipping segment. These features correspond to the three asperities commonly found from the seismological finite-source inversions. It is not possible to distinguish between the two rupture scenarios. To allow for possible mechanisms, one has to consider the possibility of rupture transfer from one segment to another and be included in probable rupture scenarios used to estimate the ground motion. Indeed, recent improvements of the geophysical observations often reveal complex fault geometries even for moderate-magnitude earthquakes, such as the 2009 Mw6.4 Suruga Bay, Japan (Aoi et al. 2010), and the Mw6.9 Iwate-Miyagi Nairiku, Japan, earthquakes (Fukuyama, 2015). In the seismological analyses, these earthquakes were mostly studied as ruptures on a single fault plane, an approximation good enough for regional or teleseismic scales.

There remains a scientific debate on the different aspects of the dynamic rupture process because the dynamics are technically difficult to solve and the frictional component of the faulting is difficult to study. However, progress over the last two decades helps us to understand various aspects of the dynamics of the earthquake mechanism. Dynamic rupture scenarios have been used to compute the ground motions for highseismic-hazard areas such as California (e.g., Olsen et al. 2009), Japan (Sekiguchi and Kase 2012), and Turkey (Aochi and Ulrich 2015). The parameter studies on dynamic rupture allow retrieving probable rupture scenarios and ground motions (e.g., Aochi et al. 2006;
Aochi and Ulrich 2015). Moreover, these dynamic simulations provide insight about the variability of the phenomena and extreme ground motions (e.g., Andrews et al. 2007).

Acknowledgments This study was launched during the French national project DEBATE (DEvelopment of Broadband Acceleration Time histories for Engineers, ended by 2012; grant ANR-08RISK-001) funded by Agence Nationale de la Recherche. We thank the project partners, R. Madariaga, F. Bonilla, A. Pecker, and C. Gélis, who have encouraged us to finalize this work, and M. Y. for the one-year grant (2009-2010) of the Program for Overseas Research from the National Institute of Advanced Industrial Science and Technology (AIST) for his stay in France. All the calculations were carried out in 2015-2016 at the French national supercomputing centers, Grand Equipement National de Calcul Intensif/Centre Informatique National de 1'Enseignement Supérieur (GENCI/CINES), and Très Grand Centre de Calcul (GENCI/TGCC), under grant no. 46700. We also benefited from the Grant-in-Aid for Scientific Research B (grant 15H02989) from Japan Society for the Promotion of Science and the Earthquake Research Institute cooperative research program (grant 2013-B05). The data for the 2007 Chuetsu-oki earthquake are provided by K-NET and KiK-net of the National Research Institute for Earth Science and Disaster Prevention (NIED) and by Tokyo Electric Power Company (TEPCO), Japan. Figure 8 is calculated with the code TF_MISFIT_GOF_CRITERIA written by Kristekova et al. (2009). We thank $\bar{S}$. Aoi and H. Sekiguchi for their source model and R. Archuleta, S. Das, R. Madariaga, and an anonymous reviewer for their comments to improve the manuscript.

\section{Appendix}

Tables 1, 2, and 3 summarize the GOF scores for each ground motion parameter by component for the three source models ( $\mathrm{K}, \mathrm{AD}$, and $\mathrm{AK})$, respectively. The average of the scores by each seismogram is shown in Fig. 10. DUR energy duration, $P G V$ peak ground velocity, $P G D$ peak ground displacement, $R S$ response spectral acceleration (averaged for periods between 1 and $10 \mathrm{~s}$ (the entire period of study), 4 and 10, 2 and 4, and 1 and $2 \mathrm{~s}$, respectively), FS Fourier spectrum (smoothed to reduce variance for frequencies between 0.1 and $1 \mathrm{~Hz}$ (the studied entire frequency), 0.1 and $0.25,0.25$ and 0.5 , and 0.5 and $1 \mathrm{~Hz}$, respectively), ENER cumulative energy (Olsen and Mayhew 2010). For some stations, we observe that the ground oscillation does not cease yet in Figs. 5, 6, and 7 by the end of the calculation ( $60 \mathrm{~s})$. In such cases, we had to cut the end of DUR automatically by the end of the calculation. This may be one of the reasons why the DUR score is not high compared to the other parameters. 
Table 1 GOF scores for the defined 13 ground motion parameters by each component of the seismograms between observation and synthetics based on source model K

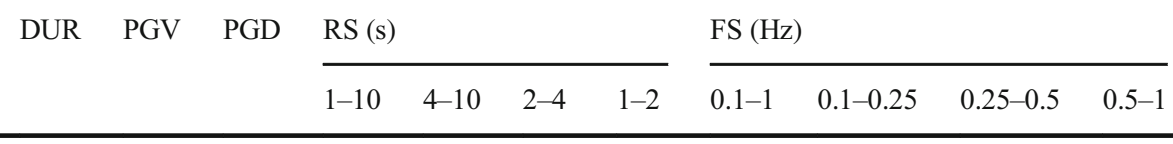

EW

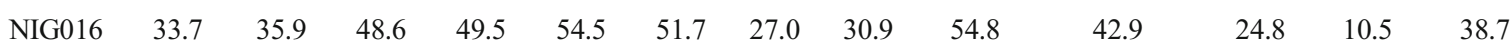

$\begin{array}{lllllllllllll}\text { NIG010 } & 33.8 & 2.2 & 1.7 & 3.0 & 2.8 & 2.9 & 7.6 & 3.3 & 2.1 & 2.2 & 6.3 & 0.6\end{array}$

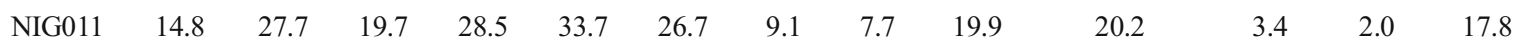

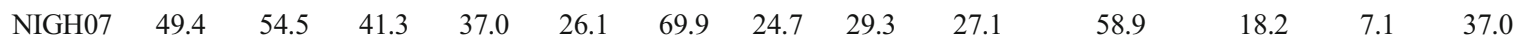

$\begin{array}{llllllllllll}\text { NIGH09 } & 67.0 & 7.9 & 23.4 & 15.1 & 28.9 & 8.3 & 2.0 & 4.3 & 51.7 & 9.5 & 2.1\end{array}$

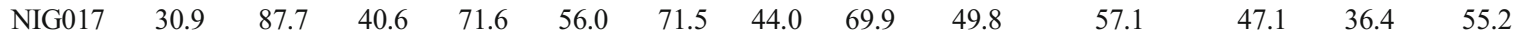

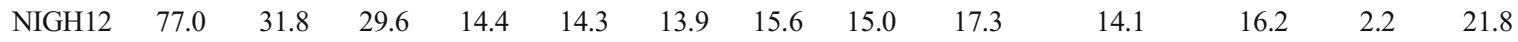

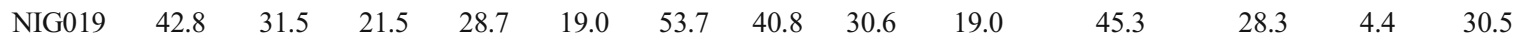

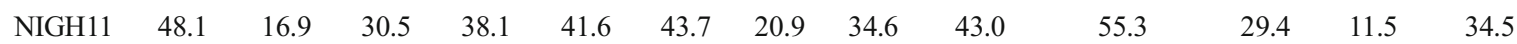

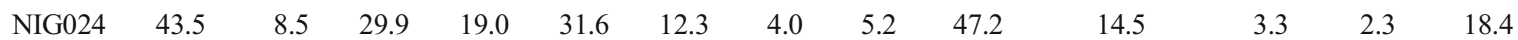

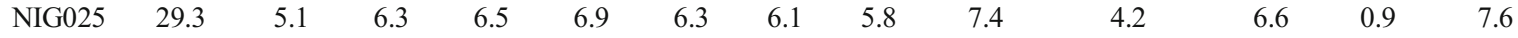

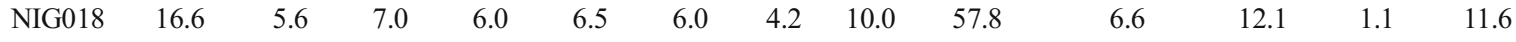

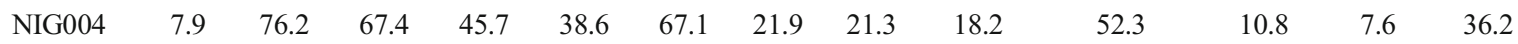

$\begin{array}{lllllllllllll}\text { Average } & 38.1 & 30.1 & 28.3 & 27.9 & 27.7 & 33.4 & 17.5 & 20.6 & 31.9 & 29.5 & 16.0 & 6.8\end{array}$
NS

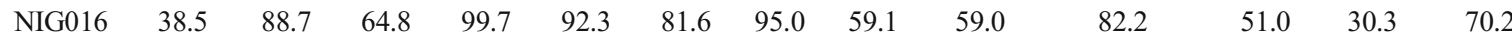

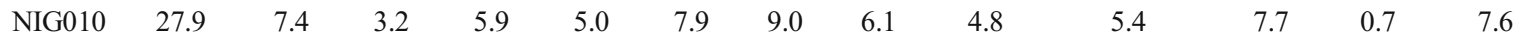

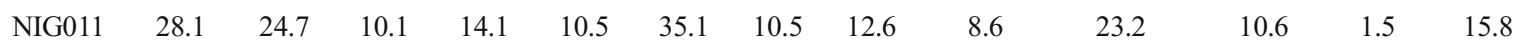

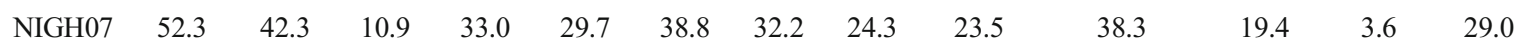

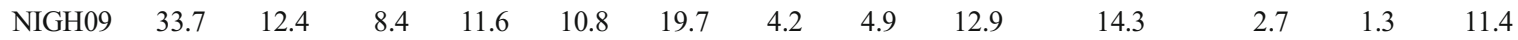

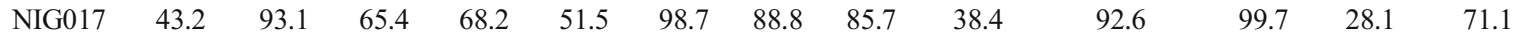

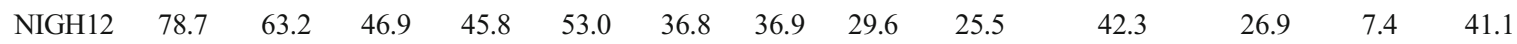

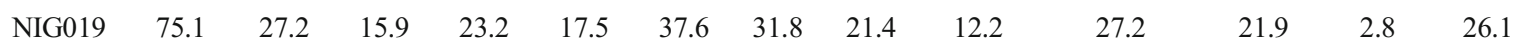

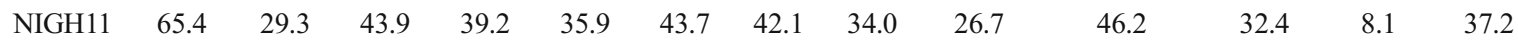

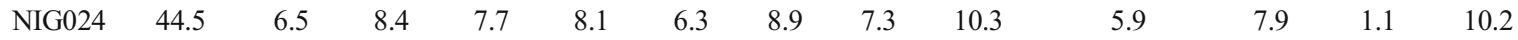

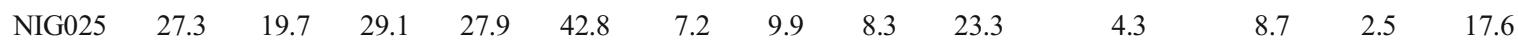

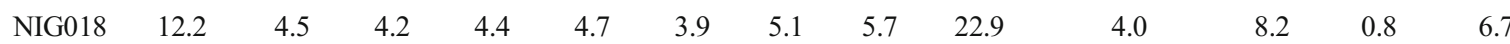

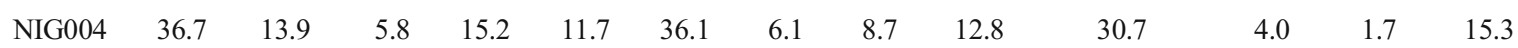

$\begin{array}{lllllllllllll}\text { Average } & 43.3 & 33.3 & 24.4 & 30.5 & 28.7 & 34.9 & 29.3 & 23.7 & 21.6 & 32.0 & 23.2 & 6.9\end{array}$
UD

\begin{tabular}{|c|c|c|c|c|c|c|c|c|c|c|c|c|c|}
\hline NIG016 & 33.4 & 72.7 & 19.8 & 64.0 & 61.9 & 72.4 & 61.4 & 51.3 & 70.3 & 40.4 & 56.5 & 14.4 & 51.5 \\
\hline NIG010 & 27.3 & 7.2 & 6.1 & 7.3 & 5.7 & 12.7 & 17.7 & 8.6 & 3.9 & 6.8 & 16.9 & 0.8 & 10.1 \\
\hline NIG011 & 35.1 & 50.4 & 31.8 & 39.8 & 39.6 & 36.5 & 50.4 & 21.6 & 30.4 & 23.7 & 22.4 & 4.3 & 32.2 \\
\hline NIGH07 & 37.9 & 45.8 & 25.2 & 43.2 & 42.0 & 59.4 & 17.0 & 35.2 & 49.4 & 68.5 & 18.4 & 11.1 & 37.8 \\
\hline NIGH09 & 49.7 & 43.4 & 33.6 & 35.6 & 33.5 & 55.0 & 12.2 & 17.1 & 48.5 & 50.8 & 7.6 & 7.1 & 32.8 \\
\hline NIG017 & 43.4 & 64.4 & 82.4 & 89.4 & 74.6 & 41.9 & 51.0 & 47.1 & 44.6 & 32.1 & 45.8 & 24.6 & 53.4 \\
\hline NIGH12 & 91.6 & 10.3 & 8.1 & 10.0 & 8.4 & 16.9 & 8.4 & 14.9 & 16.1 & 21.8 & 12.4 & 1.7 & 18.4 \\
\hline NIG019 & 60.4 & 37.3 & 49.0 & 28.7 & 28.9 & 31.9 & 21.9 & 21.7 & 28.5 & 30.1 & 19.0 & 4.2 & 30.1 \\
\hline NIGH11 & 35.4 & 26.5 & 30.3 & 30.1 & 32.2 & 32.1 & 18.5 & 18.6 & 61.9 & 20.0 & 15.7 & 5.3 & 27.2 \\
\hline NIG024 & 25.4 & 20.0 & 35.1 & 19.0 & 20.3 & 20.3 & 8.1 & 11.2 & 22.8 & 24.1 & 6.9 & 3.7 & 18.1 \\
\hline NIG025 & 22.5 & 68.1 & 90.4 & 58.6 & 75.9 & 29.5 & 31.1 & 25.9 & 99.1 & 16.8 & 22.7 & 15.8 & 46.4 \\
\hline
\end{tabular}


Table 1 (continued)

\begin{tabular}{|c|c|c|c|c|c|c|c|c|c|c|c|c|c|}
\hline & \multirow[t]{2}{*}{ DUR } & \multirow[t]{2}{*}{ PGV } & \multirow[t]{2}{*}{ PGD } & \multicolumn{4}{|c|}{ RS (s) } & \multicolumn{4}{|c|}{$\mathrm{FS}(\mathrm{Hz})$} & \multirow[t]{2}{*}{ ENER } & \multirow[t]{2}{*}{ Average } \\
\hline & & & & $1-10$ & $4-10$ & $2-4$ & $1-2$ & $0.1-1$ & $0.1-0.25$ & $0.25-0.5$ & $0.5-1$ & & \\
\hline NIG018 & 72.0 & 8.6 & 7.9 & 10.7 & 10.3 & 9.0 & 19.0 & 18.9 & 8.0 & 11.6 & 29.8 & 1.8 & 17.3 \\
\hline NIG004 & 43.6 & 15.9 & 21.4 & 22.8 & 29.1 & 15.3 & 16.4 & 16.9 & 20.0 & 27.6 & 13.4 & 2.6 & 20.4 \\
\hline Average & 44.4 & 36.2 & 33.9 & 35.3 & 35.6 & 33.3 & 25.6 & 23.8 & 38.7 & 28.8 & 22.1 & 7.5 & 30.4 \\
\hline
\end{tabular}

Table 2 GOF scores for the defined 13 ground motion parameters by each component of the seismograms between observation and synthetics based on source model AD

\begin{tabular}{|c|c|c|c|c|c|c|c|c|c|c|c|c|c|}
\hline & \multirow[t]{2}{*}{ DUR } & \multirow[t]{2}{*}{ PGV } & \multirow[t]{2}{*}{ PGD } & \multicolumn{4}{|c|}{ RS (s) } & \multicolumn{4}{|c|}{ FS (Hz) } & \multirow[t]{2}{*}{ ENER } & \multirow[t]{2}{*}{ Average } \\
\hline & & & & $1-10$ & $4-10$ & $2-4$ & $1-2$ & $0.1-1$ & $0.1-0.25$ & $0.25-0.5$ & $0.5-1$ & & \\
\hline \multicolumn{14}{|l|}{ EW } \\
\hline NIG016 & 39.7 & 66.8 & 86.7 & 78.8 & 97.9 & 41.1 & 31.9 & 53.7 & 94.0 & 34.7 & 55.4 & 34.7 & 59.6 \\
\hline NIG010 & 43.4 & 12.8 & 5.4 & 12.0 & 13.6 & 4.1 & 54.0 & 18.2 & 7.5 & 3.0 & 57.2 & 1.2 & 19.4 \\
\hline NIG011 & 26.4 & 94.4 & 40.4 & 50.2 & 60.1 & 27.1 & 52.8 & 30.9 & 38.8 & 16.8 & 38.4 & 5.3 & 40.1 \\
\hline NIGH07 & 35.6 & 58.1 & 91.7 & 70.3 & 69.3 & 86.0 & 53.6 & 92.3 & 92.0 & 71.1 & 72.8 & 61.4 & 71.2 \\
\hline NIGH09 & 57.9 & 25.7 & 40.5 & 29.8 & 52.1 & 12.9 & 7.9 & 10.6 & 72.3 & 9.8 & 8.0 & 3.0 & 27.5 \\
\hline NIG017 & 54.0 & 78.1 & 71.0 & 82.3 & 77.0 & 99.8 & 88.9 & 82.1 & 82.6 & 93.9 & 67.5 & 92.3 & 80.8 \\
\hline NIGH12 & 76.1 & 53.0 & 91.7 & 62.6 & 73.0 & 56.8 & 24.4 & 44.9 & 78.0 & 33.9 & 39.8 & 43.7 & 56.5 \\
\hline NIG019 & 82.1 & 44.6 & 50.2 & 67.1 & 81.6 & 38.8 & 50.5 & 61.6 & 73.3 & 27.3 & 68.7 & 41.8 & 57.3 \\
\hline NIGH11 & 54.6 & 85.9 & 85.9 & 83.4 & 61.8 & 90.9 & 66.6 & 98.5 & 54.8 & 94.9 & 92.2 & 89.2 & 79.9 \\
\hline NIG024 & 22.6 & 37.8 & 29.4 & 52.8 & 34.5 & 80.0 & 90.6 & 79.5 & 17.1 & 98.7 & 64.3 & 59.7 & 55.6 \\
\hline NIG025 & 44.8 & 87.7 & 71.2 & 71.8 & 72.6 & 71.5 & 70.6 & 59.2 & 27.2 & 43.6 & 70.1 & 20.6 & 59.2 \\
\hline NIG018 & 56.6 & 57.2 & 75.6 & 71.6 & 99.1 & 49.0 & 25.0 & 50.5 & 11.4 & 26.6 & 53.7 & 28.4 & 50.4 \\
\hline NIG004 & 7.3 & 80.4 & 43.1 & 96.9 & 59.9 & 17.6 & 28.5 & 29.6 & 96.6 & 14.8 & 26.0 & 72.9 & 47.8 \\
\hline Average & 46.2 & 60.2 & 60.2 & 63.8 & 65.6 & 52.0 & 49.6 & 54.7 & 57.4 & 43.8 & 54.9 & 42.6 & 54.3 \\
\hline \multicolumn{14}{|l|}{ NS } \\
\hline NIG016 & 46.3 & 45.9 & 56.5 & 66.7 & 80.8 & 44.4 & 51.0 & 57.2 & 95.6 & 26.3 & 66.6 & 30.2 & 55.6 \\
\hline NIG010 & 30.1 & 36.8 & 13.3 & 20.1 & 16.9 & 23.2 & 47.9 & 20.5 & 13.0 & 10.9 & 32.9 & 1.6 & 22.3 \\
\hline NIG011 & 32.1 & 97.6 & 59.0 & 59.5 & 55.6 & 61.0 & 78.6 & 62.4 & 32.1 & 25.9 & 89.6 & 10.4 & 55.3 \\
\hline NIGH07 & 35.1 & 53.0 & 41.8 & 96.0 & 94.4 & 62.8 & 39.2 & 96.9 & 38.0 & 37.7 & 58.4 & 24.6 & 56.5 \\
\hline NIGH09 & 31.2 & 76.7 & 30.2 & 43.1 & 55.7 & 26.0 & 32.5 & 20.4 & 60.8 & 17.1 & 19.3 & 4.6 & 34.8 \\
\hline NIG017 & 37.5 & 35.0 & 57.9 & 54.9 & 63.2 & 53.8 & 23.4 & 42.4 & 98.6 & 97.9 & 22.5 & 60.5 & 54.0 \\
\hline NIGH12 & 85.0 & 96.2 & 91.1 & 94.3 & 81.6 & 50.4 & 69.1 & 74.0 & 70.3 & 46.0 & 80.7 & 64.1 & 75.2 \\
\hline NIG019 & 90.1 & 72.1 & 58.9 & 85.6 & 79.1 & 97.1 & 97.3 & 89.5 & 83.0 & 84.2 & 91.0 & 94.8 & 85.2 \\
\hline NIGH11 & 49.3 & 88.7 & 34.7 & 58.9 & 39.2 & 82.7 & 98.5 & 99.8 & 43.7 & 61.9 & 93.4 & 65.8 & 68.1 \\
\hline NIG024 & 35.8 & 32.5 & 31.3 & 40.4 & 46.0 & 24.8 & 41.7 & 36.4 & 64.7 & 30.4 & 35.8 & 13.0 & 36.1 \\
\hline NIG025 & 33.9 & 69.2 & 82.1 & 88.6 & 98.1 & 85.4 & 60.4 & 92.6 & 66.1 & 70.9 & 75.7 & 72.6 & 74.6 \\
\hline NIG018 & 65.8 & 66.3 & 50.5 & 64.5 & 70.2 & 50.5 & 90.5 & 81.3 & 21.1 & 39.4 & 86.0 & 33.8 & 60.0 \\
\hline NIG004 & 29.9 & 42.9 & 27.9 & 42.9 & 48.9 & 33.2 & 29.2 & 25.9 & 43.3 & 22.9 & 24.8 & 9.7 & 31.8 \\
\hline Average & 46.3 & 62.5 & 48.9 & 62.7 & 63.8 & 53.5 & 58.4 & 61.5 & 56.2 & 43.9 & 59.8 & 37.4 & 54.6 \\
\hline
\end{tabular}


Table 2 (continued)

\begin{tabular}{|c|c|c|c|c|c|c|c|c|c|c|c|c|c|}
\hline & \multirow[t]{2}{*}{ DUR } & \multirow[t]{2}{*}{ PGV } & \multirow[t]{2}{*}{ PGD } & \multicolumn{4}{|c|}{ RS (s) } & \multicolumn{4}{|c|}{ FS (Hz) } & \multirow[t]{2}{*}{ ENER } & \multirow[t]{2}{*}{ Average } \\
\hline & & & & $1-10$ & $4-10$ & $2-4$ & $1-2$ & $0.1-1$ & $0.1-0.25$ & $0.25-0.5$ & $0.5-1$ & & \\
\hline \multicolumn{14}{|l|}{ UD } \\
\hline NIG016 & 45.8 & 84.2 & 27.3 & 69.4 & 61.5 & 60.0 & 71.6 & 87.8 & 51.8 & 45.2 & 56.5 & 49.7 & 59.2 \\
\hline NIG010 & 28.3 & 24.8 & 15.1 & 17.0 & 13.9 & 14.8 & 82.9 & 37.7 & 7.3 & 11.0 & 93.9 & 1.7 & 29.0 \\
\hline NIG011 & 28.1 & 95.3 & 67.0 & 99.3 & 97.0 & 74.1 & 43.1 & 91.5 & 63.8 & 42.6 & 77.0 & 47.4 & 68.9 \\
\hline NIGH07 & 28.9 & 41.2 & 81.9 & 92.6 & 99.8 & 89.7 & 59.9 & 86.1 & 88.3 & 82.8 & 66.1 & 61.3 & 73.2 \\
\hline NIGH09 & 35.1 & 73.6 & 61.6 & 78.0 & 89.5 & 56.8 & 59.7 & 52.8 & 98.9 & 45.9 & 50.3 & 29.3 & 61.0 \\
\hline NIG017 & 43.3 & 50.3 & 34.3 & 36.6 & 18.5 & 93.6 & 51.0 & 62.0 & 12.7 & 52.9 & 44.9 & 48.3 & 45.7 \\
\hline NIGH12 & 86.6 & 40.9 & 40.3 & 56.1 & 62.9 & 33.5 & 67.9 & 75.4 & 96.0 & 45.9 & 88.3 & 31.2 & 60.4 \\
\hline NIG019 & 76.9 & 79.6 & 77.8 & 94.8 & 75.0 & 57.3 & 98.5 & 96.7 & 36.2 & 33.7 & 86.3 & 95.4 & 75.7 \\
\hline NIGH11 & 51.8 & 63.2 & 46.8 & 47.3 & 37.8 & 72.0 & 69.7 & 77.2 & 26.3 & 98.9 & 77.1 & 32.0 & 58.4 \\
\hline NIG024 & 14.0 & 43.7 & 33.1 & 54.7 & 47.9 & 80.2 & 82.3 & 99.3 & 41.4 & 89.7 & 87.4 & 26.0 & 58.3 \\
\hline NIG025 & 24.9 & 28.3 & 18.2 & 51.5 & 37.9 & 94.0 & 84.1 & 94.2 & 21.9 & 71.5 & 81.0 & 33.9 & 53.5 \\
\hline NIG018 & 96.9 & 80.2 & 99.0 & 86.7 & 73.1 & 78.3 & 95.7 & 84.6 & 81.8 & 63.6 & 61.1 & 93.7 & 82.9 \\
\hline NIG004 & 20.9 & 88.9 & 45.5 & 73.5 & 42.6 & 45.6 & 65.3 & 70.9 & 63.0 & 48.4 & 69.8 & 97.8 & 61.0 \\
\hline Average & 44.7 & 61.1 & 49.8 & 66.0 & 58.3 & 65.4 & 71.7 & 78.2 & 53.0 & 56.3 & 72.3 & 49.8 & 60.5 \\
\hline
\end{tabular}

Table 3 GOF scores for the defined 13 ground motion parameters by each component of the seismograms between observation and synthetics based on source model AK

\begin{tabular}{|c|c|c|c|c|c|c|c|c|c|c|}
\hline \multirow[t]{2}{*}{ DUR } & \multirow[t]{2}{*}{ PGV } & \multirow[t]{2}{*}{ PGD } & \multicolumn{4}{|c|}{ RS (s) } & \multicolumn{4}{|c|}{ FS (Hz) } \\
\hline & & & $1-10$ & $4-10$ & $2-4$ & $1-2$ & $0.1-1$ & $0.1-0.25$ & $0.25-0.5$ & $0.5-1$ \\
\hline
\end{tabular}

\begin{tabular}{rrrrrrrrrrrrrrr}
\hline EW & & & & & & & & & & & & \\
NIG016 & 44.5 & 86.6 & 78.2 & 90.0 & 73.8 & 73.6 & 81.8 & 84.3 & 91.0 & 78.8 & 84.7 & 79.6 & 78.9 \\
NIG010 & 26.8 & 17.9 & 10.0 & 17.2 & 16.6 & 11.2 & 62.1 & 23.1 & 8.5 & 6.3 & 61.1 & 1.2 & 21.9 \\
NIG011 & 15.6 & 89.4 & 95.3 & 88.0 & 92.9 & 44.2 & 58.8 & 40.0 & 62.4 & 32.8 & 39.7 & 17.5 & 56.4 \\
NIGH07 & 53.1 & 94.7 & 72.6 & 74.3 & 57.9 & 82.0 & 77.5 & 90.4 & 73.0 & 87.5 & 82.2 & 98.5 & 78.6 \\
NIGH09 & 53.7 & 34.4 & 53.5 & 37.4 & 59.2 & 26.7 & 7.0 & 15.2 & 95.2 & 24.4 & 8.5 & 6.8 & 35.2 \\
NIG017 & 36.5 & 57.1 & 43.3 & 55.1 & 55.7 & 44.5 & 72.8 & 49.7 & 80.7 & 44.6 & 44.6 & 45.9 & 52.5 \\
NIGH12 & 77.3 & 72.3 & 99.9 & 87.6 & 89.6 & 91.0 & 70.4 & 91.9 & 54.5 & 68.7 & 79.9 & 76.9 & 80.0 \\
NIG019 & 74.7 & 79.2 & 70.2 & 88.9 & 63.6 & 47.2 & 38.4 & 72.0 & 51.2 & 52.9 & 66.3 & 90.3 & 66.2 \\
NIGH11 & 33.1 & 27.5 & 26.6 & 21.3 & 14.0 & 39.8 & 37.6 & 39.9 & 10.8 & 42.8 & 43.3 & 7.4 & 28.7 \\
NIG024 & 17.4 & 42.1 & 32.9 & 51.5 & 37.1 & 66.9 & 95.6 & 89.2 & 18.7 & 69.4 & 70.0 & 48.5 & 53.3 \\
NIG025 & 42.2 & 98.0 & 92.9 & 96.4 & 86.5 & 99.5 & 79.0 & 97.2 & 46.0 & 51.6 & 76.0 & 90.4 & 79.6 \\
NIG018 & 23.9 & 55.1 & 52.0 & 72.3 & 92.6 & 60.1 & 34.5 & 76.5 & 10.8 & 51.6 & 80.5 & 51.9 & 55.1 \\
NIG004 & 10.6 & 58.8 & 42.6 & 67.3 & 59.0 & 94.2 & 58.2 & 96.4 & 79.5 & 82.2 & 86.0 & 92.0 & 68.9 \\
Average & 39.2 & 62.5 & 59.2 & 65.2 & 61.4 & 60.1 & 59.5 & 66.6 & 52.5 & 53.4 & 63.3 & 54.4 & 58.1 \\
NS & & & & & & & & & & & & & &
\end{tabular}


Table 3 (continued)

\begin{tabular}{|c|c|c|c|c|c|c|c|c|c|c|c|c|c|}
\hline & \multirow[t]{2}{*}{ DUR } & \multirow[t]{2}{*}{ PGV } & \multirow[t]{2}{*}{ PGD } & \multicolumn{4}{|c|}{ RS (s) } & \multicolumn{4}{|c|}{ FS (Hz) } & \multirow[t]{2}{*}{ ENER } & \multirow[t]{2}{*}{ Average } \\
\hline & & & & $1-10$ & $4-10$ & $2-4$ & $1-2$ & $0.1-1$ & $0.1-0.25$ & $0.25-0.5$ & $0.5-1$ & & \\
\hline NIGH07 & 53.2 & 97.8 & 87.3 & 99.2 & 87.6 & 59.1 & 83.3 & 84.9 & 99.7 & 39.8 & 92.8 & 53.6 & 78.2 \\
\hline NIGH09 & 31.4 & 52.8 & 47.2 & 43.2 & 58.6 & 34.8 & 13.8 & 16.7 & 73.6 & 22.1 & 12.5 & 5.9 & 34.4 \\
\hline NIG017 & 42.0 & 80.3 & 48.2 & 68.2 & 70.8 & 84.7 & 35.8 & 63.1 & 93.0 & 96.7 & 40.6 & 76.2 & 66.6 \\
\hline NIGH12 & 74.8 & 62.3 & 94.6 & 56.0 & 46.3 & 71.2 & 75.9 & 85.0 & 44.4 & 82.7 & 89.8 & 56.6 & 70.0 \\
\hline NIG019 & 78.3 & 65.5 & 69.8 & 54.7 & 55.4 & 43.6 & 81.2 & 77.0 & 54.0 & 63.8 & 84.9 & 52.5 & 65.1 \\
\hline NIGH11 & 50.9 & 36.9 & 16.6 & 23.9 & 16.9 & 40.0 & 51.9 & 54.5 & 15.1 & 49.5 & 67.2 & 11.2 & 36.2 \\
\hline NIG024 & 10.9 & 93.9 & 91.9 & 92.3 & 94.7 & 76.0 & 92.5 & 80.1 & 98.4 & 55.5 & 87.5 & 66.6 & 78.4 \\
\hline NIG025 & 45.4 & 66.5 & 77.3 & 75.7 & 90.5 & 65.8 & 44.9 & 73.6 & 56.3 & 73.6 & 54.4 & 87.5 & 67.6 \\
\hline NIG018 & 6.9 & 19.4 & 19.9 & 23.8 & 36.3 & 12.6 & 21.5 & 39.8 & 32.2 & 13.0 & 66.8 & 7.1 & 25.0 \\
\hline NIG004 & 20.9 & 97.9 & 62.2 & 92.9 & 94.0 & 96.7 & 77.7 & 79.8 & 96.4 & 90.1 & 74.8 & 56.2 & 78.3 \\
\hline Average & 39.9 & 65.8 & 56.9 & 59.6 & 60.2 & 57.2 & 61.3 & 63.4 & 58.9 & 54.3 & 68.5 & 44.0 & 57.5 \\
\hline \multicolumn{14}{|l|}{ UD } \\
\hline NIG016 & 47.3 & 80.9 & 66.7 & 91.1 & 97.4 & 93.2 & 40.6 & 59.4 & 96.8 & 74.7 & 36.9 & 91.4 & 73.0 \\
\hline NIG010 & 26.7 & 42.5 & 41.4 & 30.3 & 30.9 & 16.1 & 73.2 & 33.7 & 12.5 & 12.3 & 77.7 & 4.1 & 33.4 \\
\hline NIG011 & 29.9 & 88.4 & 99.7 & 92.5 & 84.5 & 80.2 & 67.7 & 87.4 & 91.9 & 49.1 & 89.8 & 47.0 & 75.7 \\
\hline NIGH07 & 36.8 & 82.1 & 74.6 & 73.9 & 59.9 & 93.8 & 69.6 & 99.5 & 50.7 & 95.1 & 87.3 & 65.0 & 74.0 \\
\hline NIGH09 & 35.2 & 84.4 & 70.3 & 80.8 & 63.9 & 87.0 & 70.2 & 63.5 & 58.3 & 66.9 & 50.7 & 96.4 & 69.0 \\
\hline NIG017 & 31.5 & 33.9 & 21.3 & 28.0 & 14.9 & 67.4 & 47.2 & 48.1 & 6.6 & 95.6 & 42.2 & 17.4 & 37.8 \\
\hline NIGH12 & 92.9 & 64.1 & 55.0 & 55.5 & 48.4 & 83.6 & 53.6 & 69.5 & 31.4 & 96.8 & 64.2 & 32.4 & 62.3 \\
\hline NIG019 & 61.0 & 73.2 & 48.1 & 50.8 & 38.4 & 91.5 & 52.5 & 64.4 & 17.9 & 96.3 & 57.9 & 33.5 & 57.1 \\
\hline NIGH11 & 25.1 & 28.3 & 15.5 & 14.3 & 10.1 & 27.1 & 39.2 & 37.5 & 5.1 & 54.5 & 45.3 & 2.9 & 25.4 \\
\hline NIG024 & 6.1 & 41.6 & 29.3 & 47.0 & 49.5 & 42.0 & 41.4 & 60.0 & 42.4 & 70.8 & 58.8 & 26.6 & 43.0 \\
\hline NIG025 & 11.7 & 22.0 & 15.6 & 31.4 & 20.3 & 93.5 & 38.7 & 65.1 & 17.0 & 59.5 & 53.0 & 17.0 & 37.1 \\
\hline NIG018 & 82.5 & 92.3 & 68.8 & 72.2 & 52.8 & 75.3 & 89.7 & 74.8 & 63.8 & 84.9 & 58.3 & 43.8 & 71.6 \\
\hline NIG004 & 23.1 & 54.5 & 31.0 & 45.5 & 29.2 & 85.1 & 89.0 & 86.7 & 40.5 & 69.4 & 95.0 & 57.5 & 58.9 \\
\hline Average & 39.2 & 60.6 & 49.0 & 54.9 & 46.2 & 72.0 & 59.4 & 65.3 & 41.1 & 71.2 & 62.9 & 41.1 & 55.3 \\
\hline
\end{tabular}

Open Access This article is distributed under the terms of the Creative Commons Attribution 4.0 International License (http:// creativecommons.org/licenses/by/4.0/), which permits unrestricted use, distribution, and reproduction in any medium, provided you give appropriate credit to the original author(s) and the source, provide a link to the Creative Commons license, and indicate if changes were made.

\section{References}

Andrews DJ, Hanks TC, Whitney JW (2007) Physical limits on ground motion at Yucca Mountain. Bull Seism Soc Am 97: 1771-1792
Aochi H, Douglas J (2006) Testing the validity of simulated strong ground motion from the dynamic rupture of a finite fault, by using empirical equations. Bull Earthq Eng 4:211-229. doi: 10.1007/s10518-006-0001-3

Aochi H, Dupros F (2011) MPI-OpenMP hybrid simulations using boundary integral equation and finite difference methods for earthquake dynamics and wave propagation: application to the 2007 Niigata Chuetsu-Oki earthquake (Mw6.6). Procedia Comp Sci 4:1496-1505. doi:10.1016/j. procs.2011.04.162

Aochi H, Kato A (2010) Dynamic rupture of crosscutting faults: a possible rupture process for the 2007 Mw6.6 Niigata-ken Chuetsu-oki earthquake. J Geophys Res 115:B05310. doi: 10.1029/2009JB006556

Aochi H, Olsen KB (2004) On the effects of non-planar geometry for blind thrust faults on strong ground motion. Pure Appl Geophys 161:2139-2153. doi:10.1007/s00024-004-2554-X 
Aochi H, Ulrich T (2015) A probable earthquake scenario near Istanbul determined from dynamic simulations. Bull Seism Soc Am 105(3):1468-1475. doi:10.1785/0120140283

Aochi H, Madariaga R, Fukuyama E (2003) Constraint of fault parameters inferred from nonplanar fault modeling. Geochem, Geophys, Geosyst 4(2):1020. doi:10.1029/ 2001GC000207

Aochi H, Cushing M, Scotti O, Berge-Thierry C (2006) Estimating rupture scenario likelihood based on dynamic rupture simulations: the example of the segmented Middle Durance fault, southeastern France. Geophys J Int 165:436446. doi:10.1111/j.1365-246X.2006.0284.x

Aochi H, Ducellier A, Dupros F, Delatre M, Ulrich T, de Martin F, Yoshimi M (2013a) Finite difference simulations of seismic wave propagation for the 2007 Mw6.6 Niigata-ken Chuetsuoki earthquake: validity of models and reliable input ground motion in the near field. Pure Appl Geophys 170:43-64. doi: 10.1007/s00024-011-0249-5

Aochi H, Ulrich T, Ducellier A, Dupros F, Michea D (2013b) Finite difference simulations of seismic wave propagation for understanding earthquake physics and predicting ground motions: advances and challenges. J Phys Conf Ser 454: 012010. doi:10.1088/1742-6596/454/1/012010

Aoi S, Sekiguchi H, Morikawa N, Kunugi T (2008) Source process of the 2007 Niigata-ken Chuetsu-oki earthquake derived from near-fault strong motion data. Earth Planets Space 60:1131-1135

Aoi S, Enescu B, Suzuki W, Asano Y, Obara K, Kunugi T, Shiomi K (2010) Stress transfer in the Tokai subduction zone from the 2009 Suruga Bay earthquake in Japan. Nat Geosci 3:496500. doi: $10.1038 /$ ngeo 885

Aoki Y, Furuya M, Kato T (2008) Coseismic deformation due to the 2007 Chuetsu-oki earthquake $(\mathrm{Mw}=6.8)$. Earth Planets Space 60:1075-1080

Baumann C, Dalguer LA (2014) Evaluating the compatibility of dynamic rupture-based synthetic ground motion with empirical ground-motion prediction equation. Bull Seism Soc Am 104:634-652. doi:10.1785/0120130077

Crempien JG, Archuleta RJ (2015) UCSB method for simulation of broadband ground motion from kinematic earthquake sources. Seism Soc Lett 86:61-67. doi:10.1785/0220140103

Douglas J, Aochi H (2008) A survey of techniques for predicting earthquake ground motions for engineering purposes. Surv Geophys 29:187-220

Douilly R, Aochi H, Calais E, Freed AM (2015) 3D dynamic rupture simulations across interacting faults: the $\mathrm{Mw} 7.0$, 2010, Haiti earthquake. J Geophys Res 120:1108-1128. doi:10.1002/2014JB011595

Dunham EM, Bhat HS (2008) Attenuation of radiated ground motion and stresses from three-dimensional supershear ruptures. J Geophys Res 113:B08319. doi:10.1029/ 2007JB005182

Fujiwara H, Kawai S, Aoi S, Senna S, Ooi M, Matsuyama H, Iwamoto K, Suzuki H, Hayakawa Y (2009) A subsurface structure modeling of whole of Japan for strong-motion evaluation. Proceedings of the 12th Japan Earthquake Engineering Symposium, pp 1466-1469 (in Japanese with English abstract)

Fukuyama E (2015) Dynamic faulting on a conjugate fault system detected by near-fault tilt measurements. Earth Planets Space 67:38. doi:10.1186/s40623-015-0207-1
Graves RW, Pitarka A (2015) Broadband ground-motion simulation using a hybrid approach. Bull Seismol Soc Am 100: 2095-2123. doi:10.1785/0120100057

International Atomic Energy Agency (IAEA) (2007) Preliminary findings and lessons learned from the 16 July 2007 earthquake at Kashiwazaki-Kariwa NPP. Mission report, V. 1, International Nuclear Information System, 40(3), RN40010606, 17th August 2007. Accessible from https:// www.iaea.org/inis/

Irikura K (2008) Lesson from the 2007 Niigata-ken Chuetsu-oki earthquake on seismic safety for nuclear power plant. Bull Japan Asso Earthq Eng 7:25-29 (in Japanese)

Irikura K (2010) Further advancement of strong motion evaluation-expectation for deep boreholes seismic observation and geophysical exploration from viewpoint of ground motion evaluation. 1st Kashiwazaki International Symposium on Seismic Safety of Nuclear Installations "Mission for Technology Innovation toward Next Generation", 24-26 November 2010, Kashiwazaki, Japan

Irikura K, Miyake H (2011) Recipe for predicting strong ground motion from crustal earthquake scenarios. Pure Appl Geophys 168:85-104. doi:10.1007/s00024-010-0150-9

Kato A, Sakai S, Kurashimo E, Igarashi T, Iidaka T, Hirata N, Iwasaki T, Kanazawa T, Group for the Aftershock Observations of the 2007 Niigataken Chuetsu-oki Earthquake (2008) Imaging heterogeneous velocity structures and complex aftershock distributions in the source region of the 2007 Niigataken Chuetsu-oki earthquake by a dense seismic observations. Earth Planets Space 60:1111-1116

Kristekova M, Kristek J, Moczo P (2009) Time-frequency misfit and goodness-of-fit criteria for quantitative comparison of time signals. Geophys J Int 178:813-825

Mai PM, Beroza GC (2002) A spatial random-field model to characterize complexity in earthquake slip. J Geophys Res 107(B11):2308. doi:10.1029/2001JB000588

Miyake H, Koketsu K, Hikima K, Shinohara M, Kanazawa T (2010) Source fault of the 2007 Chuetsu-oki, Japan, earthquake. Bull Seismol Soc Am 100:384-391. doi:10.1785/ 0120090126

Nishimura T, Tobita M, Yarai H, Ozawa S, Murakami M, Yutsudo T, Ishimoto M, Umesawa T, Toyofuku T, Kawamoto S, Amagai T, Fujiwara M, Suzuki A, Enya S, Sasaki T, Yokokawa M, Oomori S, Tanoue S, Ikeda H, Nemoto M, Suito H, Hayashi F, Une H, Koarai M, Tsuzawa M (2008) Crustal deformation and a preliminary fault model of the 2007 Chuetsu-oki earthquake observed by GPS, InSAR, and levelling. Earth Planets Space 60:1093-1098

Oglesby DD, Day SM (2002) Stochastic fault stress: implications for fault dynamics and ground motion. Bull Seismol Soc Am 92:3006-3021

Olsen KB, Mayhew JE (2010) Goodness-of-fit criteria for broadband synthetic seismograms, with application to the 2008 Mw5.4 Chino Hills, CA, earthquake. Seismol Res Lett 81:715-723

Olsen KB, Takedatsu R (2015) The SDSU broadband groundmotion generation module BBtoolbox version 1.5. Seismol Soc Lett 86:81-88. doi:10.1785/0220140102

Olsen KB, Madariaga R, Archuleta RJ (1997) Three-dimensional dynamic simulation of the 1992 Landers earthquake. Science 278:834-838

Olsen KB, Day SM, Dalguer L, Mayhew L, Cui Y, Zhu J, CruzAtienza VM, Roten D, Maechling P, Jordan TH, Chourasia A 
(2009) ShakeOut-D: ground motion estimates using an ensemble of large earthquakes on the Southern San Andreas fault with spontaneous rupture propagation. Geophys Res Lett 36:L04303. doi:10.1029/2008GL036832

Peyrat S, Olsen KB, Madariaga R (2001) Dynamic modeling of the 1992 Landers earthquake. J Geophys Res 106:26467-26482

Peyrat S, Olsen KB, Madariaga R (2004) Which dynamic rupture parameters can be estimated from strong ground motion and geodetic data? Pure Appl Phys 161:2155-2169

Ruiz S, Madariaga R (2011) Determination of the friction law parameters of the Mw6.7 Michilla earthquake in northern Chile by dynamic inversion. Geophys Res Lett 38:L09317. doi:10.1029/2011GL047147

Schmedes J, Archuleta RJ (2008) Near-source ground motion along strike-slip faults: insights into magnitude saturation of PGV and PGA. Bull Seismol Soc 98:2278-2290

Sekiguchi H, Kase Y (2012) Fault specific, dynamic rupture scenarios for strong ground motion prediction. Proceeding of 15th World Conference on Earthquake Engineering, Paper ID 4965, Lisbon, Portugal, September 2012
Sekiguchi H, Yoshimi M, Horikawa H, Yoshida K, Suzuki H, Matsuyama H, Morino M, Takizawa F, Ying L (2009) 3D subsurface structure model of the Niigata sedimentary basin. Geological Survey of Japan-AIST annual report on active fault and paleoearthquake researches, 9, 175-259 (in Japanese with English abstract)

Shinohara M, Kanazawa T, Yamada T, Nakahigashi K, Sakai S, Hino R, Murai Y, Yamazaki A, Obana K, Ito Y, Iwakiri K, Miura R, Machida Y, Mochizuki K, Uehira K, Takara M, Kuwano A, Amamiya S, Kodaira S, Takanami T, Kaneda Y, Iwasaki T (2008) Precise aftershock distribution of the 2007 Chuetsu-oki earthquake obtained by using an ocean bottom seismometer network. Earth Planets Space 60:1121-1126

Song SG, Dalguer LA, Mai PM (2013) Pseudo-dynamic source modeling with 1-point and 2-point statistics of earthquake source parameters. Geophys J Int 196:1770-1786. doi:10. 1093/gji/ggt479

Strasser FO, Bommer JJ (2009) Large-amplitude ground-motion recordings and their interpretations. Soil Dyn Earthq Eng 29: 1305-1329. doi:10.1016/j.soildyn.2009.04.001 